\title{
Article
}

\section{Fluid-Structure Interaction of a Foiling Craft}

\author{
Laura Marimon Giovannetti $^{1, *(\mathbb{D}}$, Ali Farousi ${ }^{2}$, Fabian Ebbesson ${ }^{2}$, Alois Thollot ${ }^{3}$, Alex Shiri ${ }^{1}$ \\ and Arash Eslamdoost ${ }^{2}$
}

Citation: Marimon Giovannetti, L.; Farousi, A.; Ebbesson, F.; Thollot, A.; Shiri, A.; Eslamdoost, A. FluidStructure Interaction of a Foiling Craft. J. Mar. Sci. Eng. 2022, 10, 372. https://doi.org/10.3390/ jmse10030372

Academic Editors: Carlo Bertorello and Andrea Ratti

Received: 31 January 2022

Accepted: 2 March 2022

Published: 6 March 2022

Publisher's Note: MDPI stays neutral with regard to jurisdictional claims in published maps and institutional affiliations.

Copyright: (C) 2022 by the authors. Licensee MDPI, Basel, Switzerland. This article is an open access article distributed under the terms and conditions of the Creative Commons Attribution (CC BY) license (https:// creativecommons.org/licenses/by/ $4.0 /)$.
1 SSPA Sweden AB, Research Group, 40022 Gothenburg, Sweden; alex.shiri@sspa.se

2 Mechanics and Maritime Sciences, Division of Marine Technology, Chalmers University of Technology, 40022 Gothenburg, Sweden; farousi@student.chalmers.se (A.F.); fabebb@student.chalmers.se (F.E.); arash.eslamdoost@chalmers.se (A.E.)

3 INP ENSEEIHT, 31000 Toulouse, France; alois.thollot@gmail.com

* Correspondence: laura.marimon@sspa.se

\begin{abstract}
Hydrofoils are a current hot topic in the marine industry both in high performance sailing and in new passenger transport systems in conjunction with electric propulsion. In the sailing community, the largest impact is seen from the America's cup, where boats are sailed at more than 50 knots (over $100 \mathrm{~km} / \mathrm{h}$ ) with 100\% "flying" time. Hydrofoils are also becoming popular in the Olympics, as in the 2024 Olympic games 5 gold medals will be decided on foiling boats/boards. The reason for the increasing popularity of hydrofoils and foiling boats is the recent advances in composite materials, especially in their strength to stiffness ratio. In general, hydrofoils have a very small wetted surface area compared to the wetted surface area of the hull. Therefore, after "take-off" speed, the wetted surface area of the hull, and consequently the resistance of the boat, is reduced considerably. The larger the weight of the boat and crew and the higher the speeds, the greater the loads on the hydrofoils will be. The current research investigates the interaction effects between the fluid and structure of the ZP00682 NACRA 17 Z-foil. The study is carried out both experimentally, in SSPA's cavitation tunnel, and numerically using a fully coupled viscous solver with a structural analysis tool. The experimental methodology has been used to validate the numerical tools, which in turn are used to reverse engineer the material properties and the internal stiffness of the NACRA 17 foil. The experimental flow speed has been chosen to represent realistic foiling speeds found in the NACRA 17 class, namely 5, 7, and $9 \mathrm{~m} / \mathrm{s}$. The forces and the deflection of the Z-foil are investigated, showing a maximum deflection corresponding to $24 \%$ of the immersed span. Finally, the effects of leeway and rake angles on the bending properties of the Z-foil are investigated to assess the influence of different angles in sailing strategies, showing that a differential rake set-up might be preferred in search for minimum drag.
\end{abstract}

Keywords: foiling; fluid structure interaction; experimental methods; numerical simulations

\section{Introduction}

The NACRA 17 is a high-performance catamaran that was specifically designed to meet the criteria required by World Sailing, the world governing body for the sport of sailing. Designed in 2011 by a collaboration between Morrelli amd Melvin, NACRA, and the builders CMI, the NACRA 17 was selected as the mixed multihull class for the 2016 Olympics [1]. Since the Rio Olympics, which featured curved dagger boards (C-foils), a design modification was presented to allow the use of hydrofoiling daggerboards (Z-foils) and T-shaped rudders, allowing the boat to become a fully foiling platform for Tokyo 2020 [2]. The new version of the NACRA 17, MK-II, is designed to be a 4-point fully foiling catamaran with the 4 hydrofoils remaining in the water at all times in order to achieve adequate lift and heave stability. The pitching moment, seen in Figure 1, is opposed longitudinally in three ways:

- $\quad$ Adjusting the weight of the crews that constantly move along the hull; 
- Actively changing the rake angle of the daggerboards with a range of $-3^{\circ}$ to $6^{\circ}$. This can be done with a series of pulley systems whilst sailing. The daggerboards can be independently moved, giving the possibility of having the windward and leeward daggerboard on different and even opposing rake angles;

- Adjusting the rake of the T-rudders whilst stationary on land or in between races. The rake range in the rudders varies approximately between $-0.5^{\circ}$ to $2.5^{\circ}$.

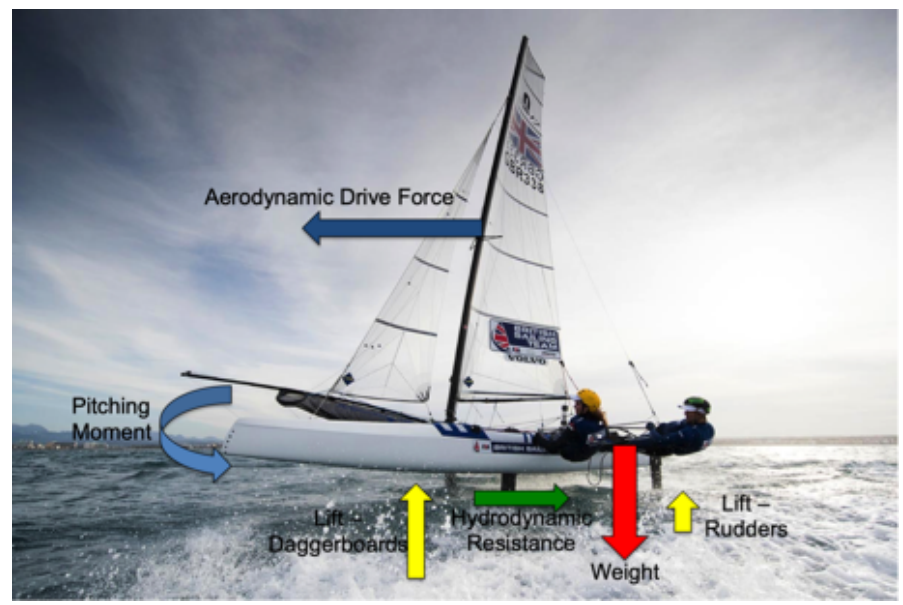

Figure 1. Longitudinal balance of forces on a NACRA 17 foiling catamaran.

The main particulars of the NACRA 17 are detailed in Table 1.

Table 1. NACRA 17 particulars.

\begin{tabular}{ccc}
\hline Particular & Dimension & Unit \\
\hline Length Overall (LOA) & 5.25 & $\mathrm{~m}$ \\
Waterline Length (LWL) & 5.15 & $\mathrm{~m}$ \\
Overall beam & 2.59 & $\mathrm{~m}$ \\
Hull beam & 0.40 & $\mathrm{~m}$ \\
Boat weight (dry condition-minimum) & 163 & $\mathrm{~kg}$ \\
Crew weight & $131-148$ & $\mathrm{~kg}$ \\
Mainsail area & 16.1 & $\mathrm{~m}^{2}$ \\
Jib area & 4.0 & $\mathrm{~m}^{2}$ \\
Gennaker area & 17.9 & $\mathrm{~m}^{2}$ \\
Z-Foil span & 1.9 & $\mathrm{~m}$ \\
Z-Foil chord & 0.238 & $\mathrm{~m}$ \\
Z-Foil t/c & 0.16 & - \\
\hline
\end{tabular}

For the purpose of this research, the main investigated items are the Z-foil daggerboards, and especially their stiffness accuracy and deflection under load. In previous studies [3], large variation in bending stiffness was recorded for a range of foils. The aim of the research is therefore to reverse engineer the internal properties of the Z-foil to replicate a realistic sailing load numerically, thus understanding the implications of sailing with a more flexible or a stiffer daggerboard as well as the influence of the rake and leeway angle on the overall deflection and forces magnitudes.

Hydrodynamic performances of foils were traditionally carried out considering the structure in its rigid form. However, taking into consideration and recognizing the deflected shapes in the assessment of the performances will enable a further understanding of the sailing equipment, introducing Fluid Structure Interaction (FSI) research in equipment choice. Indeed, both the bend and the twist of the hydrofoil could dramatically impact the performance of the hydrofoil, and with the NACRA 17 being a catamaran, having a consistent stiffness across both starboard and port foil is a key factor for flight stability. 
Figure 2 shows that the flexibility of the structures not only needs to be considered from a pure performance evaluation of lift, drag, and side-force, but could also determine more complex scenarios such as surface piercing, ventilation, and cavitation when the part of the foil that contributes to vertical lift, which normally is fully immersed, pierces the free-surface of the water, effectively changing the density of the flow surrounding it.

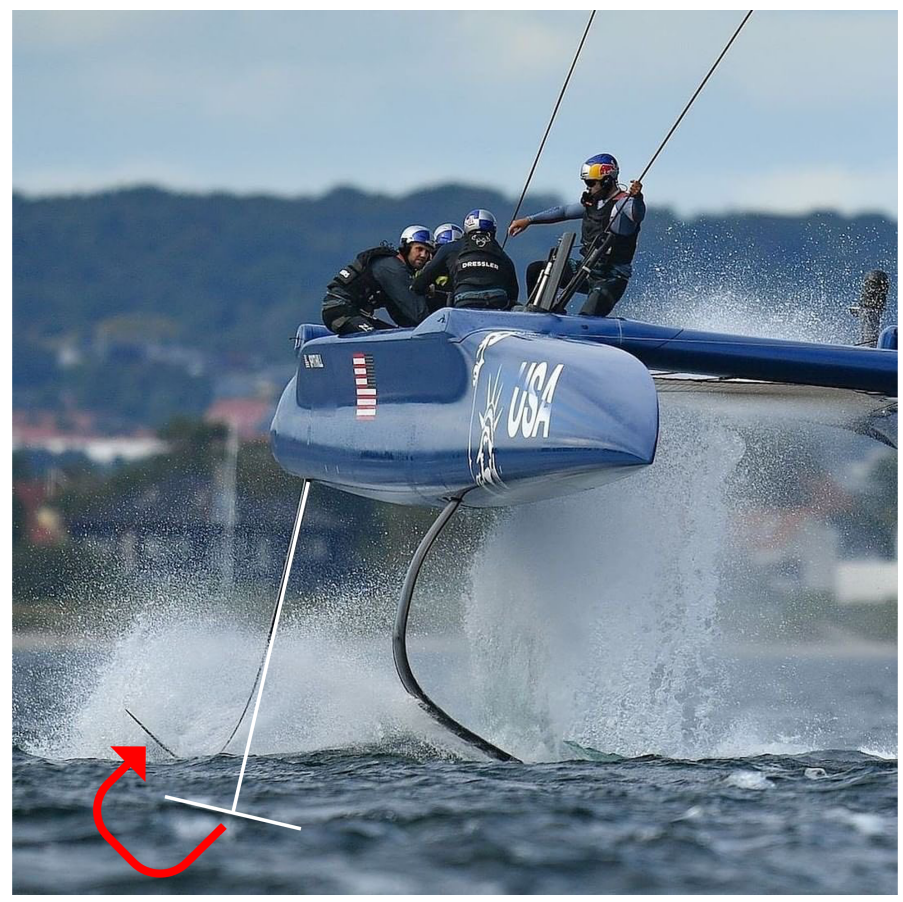

Figure 2. Example of large rudder deflection during sailing load of the Team USA high-performance catamaran from the F50 fleet in a SailGP event.

This research project presents the results of FSI investigations on a full-size NACRA 17 Z-Foil port side daggerboard. The research entails experiments in SSPA's cavitation tunnel, inside the medium size test section that can replicate Reynolds number similarity for fully foiling scenarios, and of a fully coupled numerical analysis using Star-CCM+ and ABAQUS commercial software coupled through the co-simulation engine. After an introduction of the FSI problems that affect hydrofoils, an accurate description of the investigated specimen both in the experimental and numerical environment is presented. Finally the results are reported and discussed, ensuring a correspondence to the possible real life sailing set-ups.

\section{Background on Fluid-Structure Interaction}

According to [4], fluid-structure interaction is a type of problem where the fluid and the solid parts influence each other mutually. The flow field around the solid structure depends on the shape and the motion of the structure. In contrast, the solid structure's deformation and its motion depend on the resultant pressure and shear forces extracted from the fluid on the structure. FSI problems can be noticed in both nature, i.e., a tree with the wind, and in the different industrial applications, i.e., marine applications at seas such as hydrofoils [5]. The interaction effects are sometimes prominent and crucial for the design of many engineering applications and therefore should not be disregarded in their design process.

Advancement in composite materials allowed us to design reliable structures capable of sustaining extreme deformation without failure during normal operation. The wind turbine industry is leading the investigation on shape-adaptive blades, as turbine performance could be increased in a wide range of operational conditions by employing passive adaptation of the blade twist. Herath et al. [6] investigated the concept of Differential Stiffness Bend-Twist to control the blade deformation by developing a numerical algorithm that determines the required composite layup to achieve optimal flexure stiffness value in 
the blade structure. Herath et al. [7] later applied the bend-twist coupling in the design of hydrofoils and tested them in a water tunnel, which showed an increase in the Lift to Drag ratio of the foils. Light weight composite structures are desirable for high performance foiling marine vessels and are almost exclusively used in hydrofoil construction.

Flexibility of the composite foil could be either by design or the consequence of choosing a flexible material for the component. While scientific studies follow the first approach, in most commercial designs a dynamic response under variable load is too complex and therefore undesirable. In both cases, numerical simulation and/or experimental tests are necessary to predict the performance of the component. Studies like [8,9] were dedicated to predict the hydro-elastic response of particular hydrofoil using coupled CFD-FEM simulation and validating the result in measurement tests. Many studies, such as [10], aim to improve and validate the numerical scheme used in Fluid-Structure Interaction simulation, as the computational cost of viscous flow CFD coupled with FEM solver is usually high. Specific issues like cavitating flexible hydrofoil were also investigated under different flow regimes in studies by Ducoin et al. [11].

Numerical simulation of the fluid-structure interactions can be categorized based on the way which information for the solution is shared between the fluid solver and structure solver. In a fully coupled FSI problem (two-way coupling), fluid and solid particles at the coupled interface move with the same kinematics (position, velocity, and acceleration) and experience the same traction. However, in one-way coupling simulations, only the fluid forces acting on the structure is transferred to the structure solver. Since composite hydrofoils show a considerable deflection and twist under different loading conditions, a two-way numerical coupling approach is employed in the current research.

\section{Geometries and Reference Systems}

The FSI experiment was conducted in SSPA's cavitation tunnel. The tunnel's crosssectional dimensions are $2.1 \mathrm{~m} \times 1.22 \mathrm{~m}$ with a maximum speed of $9.9 \mathrm{~m} / \mathrm{s}$. The tunnel contains three main sections: inlet, outlet, and a middle body section (test section). The total longitudinal length of the middle section is $8 \mathrm{~m}$.

After analyzing the performances of the NACRA 17 class with data analysis tools such as the ones available at SAP Analytics [12], three test speeds were chosen, namely $5 \mathrm{~m} / \mathrm{s}$, $7 \mathrm{~m} / \mathrm{s}$ and $9 \mathrm{~m} / \mathrm{s}$, representative of slow, medium, and high foiling speeds, respectively.

Due to the test section dimensions, the Z-Foil is immersed in $1.01 \mathrm{~m}$ of water, as seen in Figure 3c, with the clamping mechanism replicating the NACRA 17 hull depth above the test section roof. This configuration simulates a flight height of approximately $400 \mathrm{~mm}$. It should be noted that there is no free-surface present inside the tunnel and the foil immersion is measured from the upper wall of the tunnel. In the NACRA 17 Velocity Prediction Program (VPP) presented by [13], a flight height of $400 \mathrm{~mm}$ is considered a medium height above the water, with maximum flight height considered to be near the region of the elbow.

The following test matrix was measured during the tests:

- Leeway angle: $\mathrm{T}=-2.5^{\circ},-1^{\circ},-0.5^{\circ}, 0^{\circ}, 0.5^{\circ}, 1^{\circ}, 2.5^{\circ}, 3.5^{\circ}$;

- $\quad$ Rake angle: $\mathrm{R}=-2^{\circ},-1^{\circ}, 0^{\circ}, 1^{\circ}, 2^{\circ}, 3^{\circ}, 4^{\circ}, 5^{\circ}, 5.5^{\circ}$;

- Speed: $\mathrm{U}=5 \mathrm{~m} / \mathrm{s}, 7 \mathrm{~m} / \mathrm{s}, 9 \mathrm{~m} / \mathrm{s}$.

The coordinate systems considered in the experiments and in the numerical analyses can be seen in Figure 3. The experimental coordinate system are referred to as $F_{X}, F_{Y}$ and $F_{Z}$. The results presented in the current research are converted to Lift and Drag for each investigated leeway and rake angle, to compare the experimental and the numerical forces acting on the foil.

The range of leeway angles $(T)$ was chosen to represent both the windward and leeward foils, also considering the toe-out angle of $1^{\circ}$ set by the manufacturer, as shown in the schematic in Figure 4. With a nominal leeway angle $(T)$ for a NACRA 17 ranging around $2.5^{\circ}$ to $3^{\circ}$, as assessed with drone footage [2], the leeward foil would experience 
a different angle of attack than the windward foil, with the windward foil subject to a negative angle of attack and the leeward foil to a very small positive angle.

The rake angle $(R)$ on the boat can be set to a range of $-3^{\circ}$ to $6^{\circ}$. The true rake angle and the overall range values could however vary slightly with manufacturing accuracy on applying the rake indicator on the hull, as highlighted in [14]. In the investigated cases, the minimum range is set to $-2^{\circ}$ and the maximum is set to $4-5.5^{\circ}$ due to the maximum allowable forces and moments from the 6-components balance.
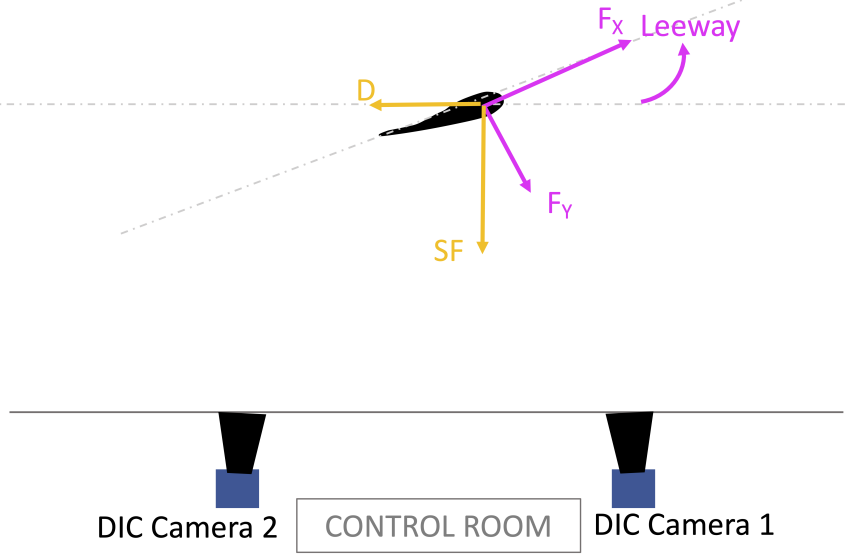

(a) Top view

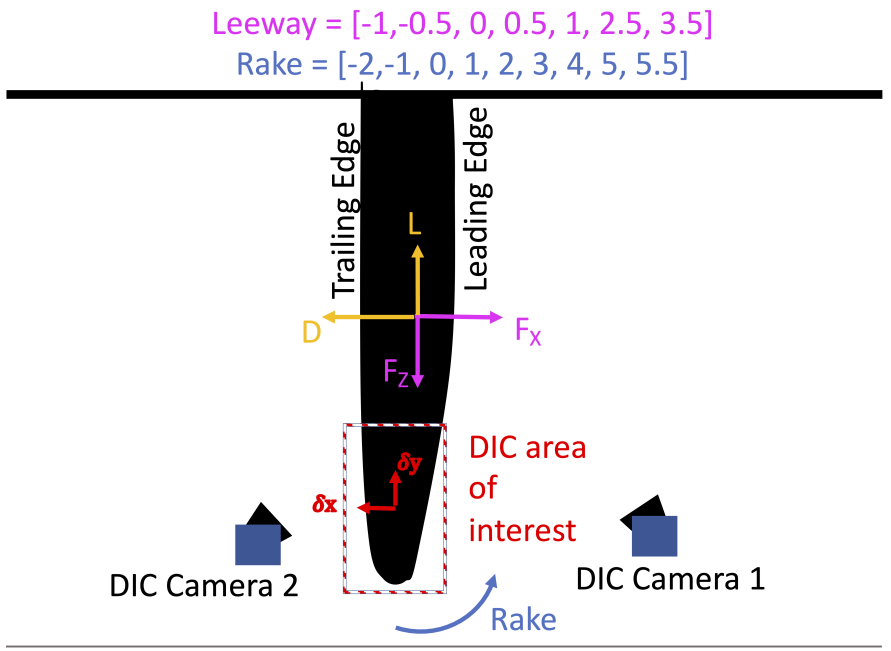

(b) Side view; L, D is in the tunnel coordinate and $F_{x}, F_{y}$ is in the foil coordinate.

Figure 3. Cont. 

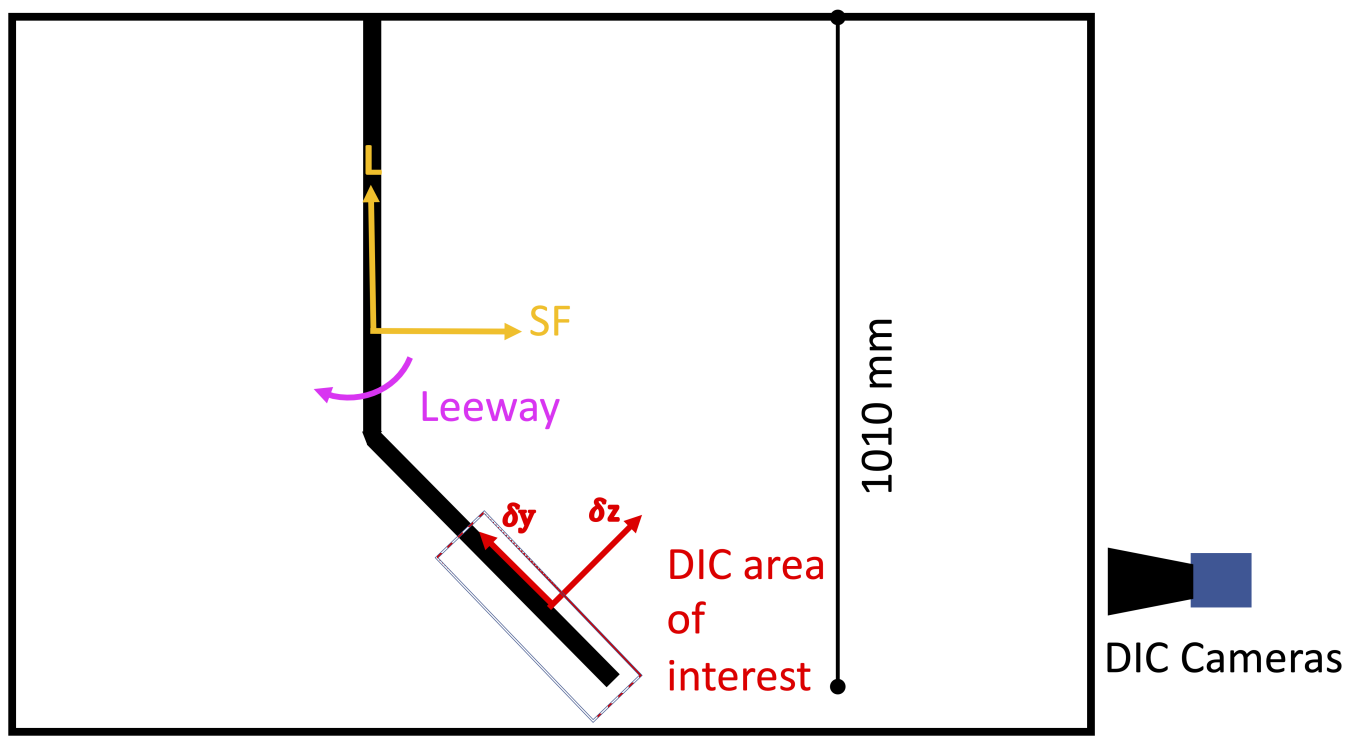

(c) Rear view

Figure 3. Reference systems for the investigated forces, leeway and rake angles, and measured deflections. The arrows point toward the positive directions.

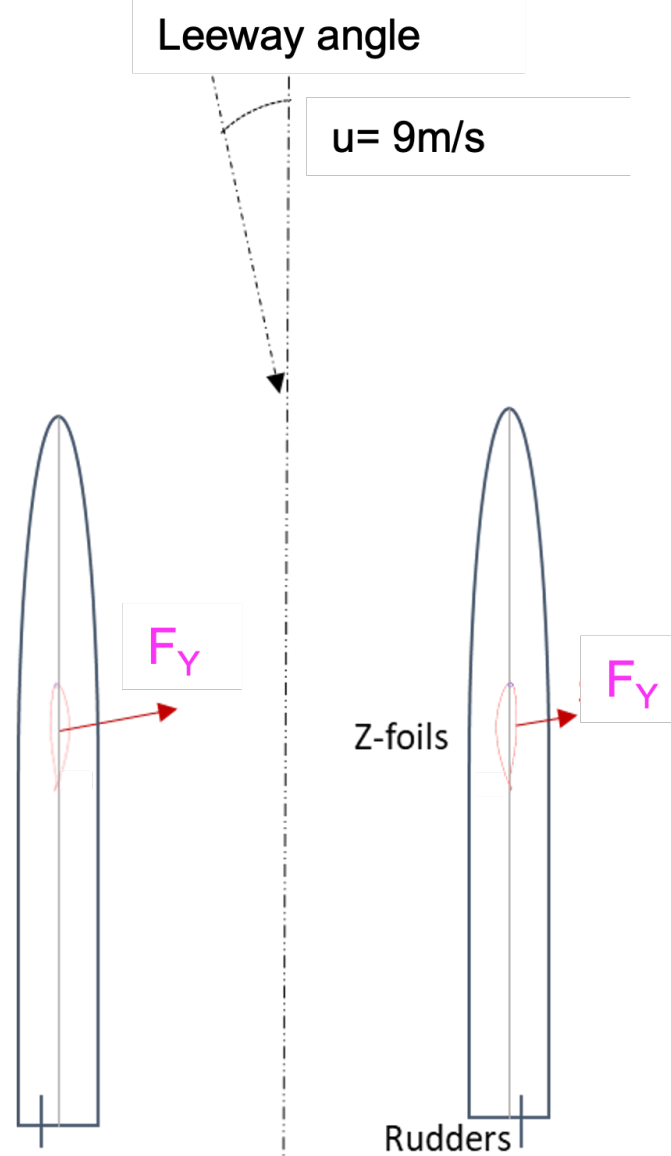

Figure 4. NACRA 17 schematics of side force generation from the leeward and windward Z-foils. 
The overall dimensions of the tested NACRA 17 Z-foil and its cross-sectional shape can be seen in Figure 5. The tested foil was a port daggerboard with serial number ZP00682. In order to run accurate numerical simulations, and to best understand the implications of deflection on the performances of the foil, it is necessary to acquire a digitized geometry. The foil was therefore 3D-scanned using an Artec3D-Eva scanner. The hand-held scanner has a linear accuracy of $0.1 \mathrm{~mm}$. The 3D scan was used to produce a stereolitography (stl) representation of the Z-foil. The stl is basically a tessellated surface, that does not present enough data points near edge regions, like the leading edge, to immediately be used in a numerical simulations. Therefore, in order to create a three-dimensional hydrofoil geometry usable in the numerical environment, the stl was initially imported to Autodesk Inventor, a CAD software, where a series of span-wise cross sections were extracted along the hydrofoil, see Figure 6. Moreover, to smooth the profiles, a series of spline curves were fitted to the extracted cross sections. Finally, a surface was lofted between the splines. The trailing edge thickness is kept to $2 \mathrm{~mm}$, replicating the design specification of the $Z$-foil daggerboard. This manipulated geometry is then verified against the initial 3D scanned stl using CloudCompare, an open source software to align and compare 3D models. CloudCompare calculates the RMS value of the distance between two models as shown in Figure 7. The comparative result shown in the figures confirms that the recreated hydrofoil surface aligns well within the original surface data obtained from the 3D-scanner.

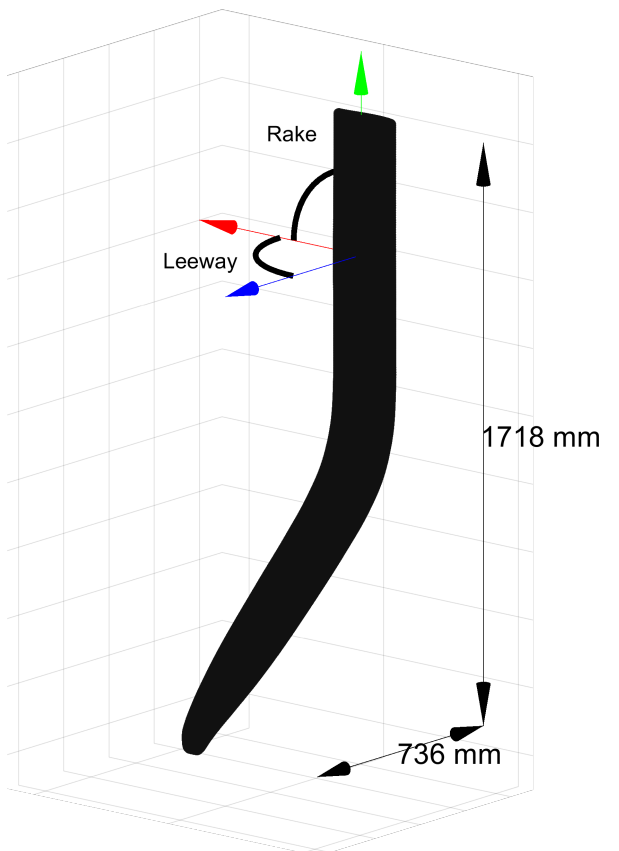

(a) Overall dimensions

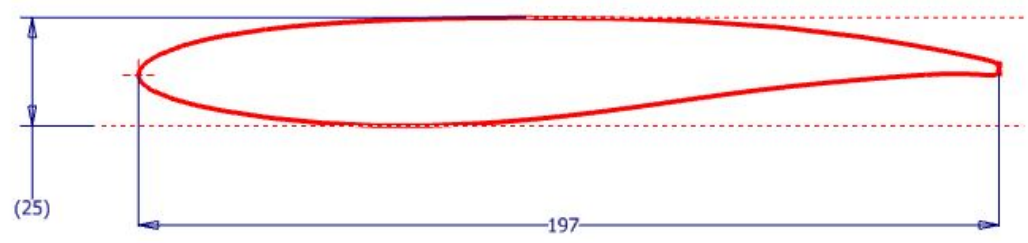

(b) Cross section around the elbow

Figure 5. Main dimensions of the hydrofoil. Cross section taken from the elbow of the hydrofoil. 


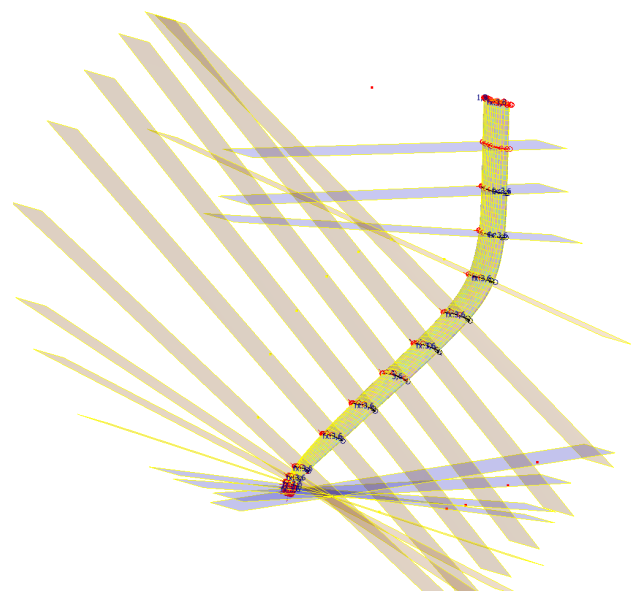

Figure 6. Planes used for extraction of normal span-wise cross sections along the foil to create the geometry for the numerical simulations.

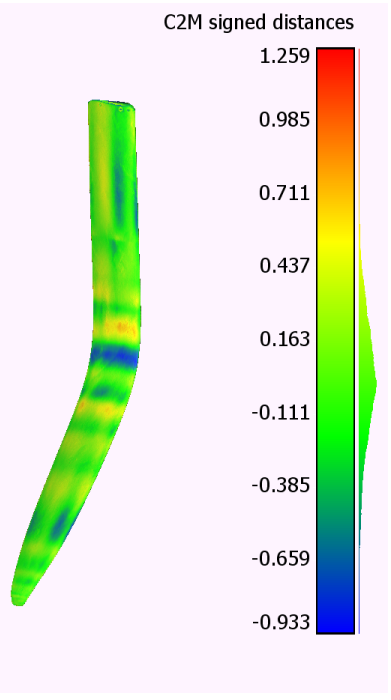

(a) Isometric view

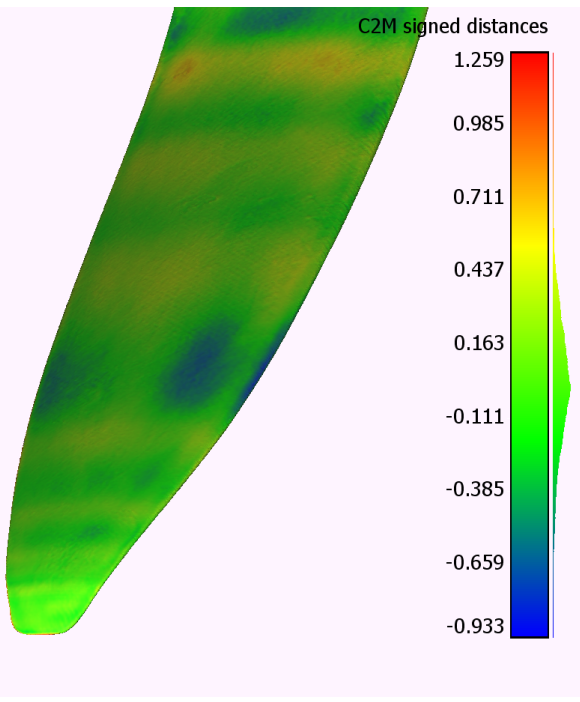

(b) Detailed view of the leading edge

Figure 7. Cloud to mesh (C2M) of the NACRA 17 Z-Foil geometry as designed with cross-section planes and lofting compared to 3D-scan with differences presented in $\mathrm{mm}$.

Despite the accurate external shape obtained from the 3D-scan, there were still some unknown aspects of the geometry of the hydrofoil, mainly its internal structure and the composition of the composite laminate stack. The hydrofoil was tested non-destructively, thus, investigating its internal structure was not possible. An attempt to figure out the location of the assumed stiffener was made by knocking on the hydrofoil and listening to the change in the sound pitch generated from the taps. A distinct difference in pitch was identified just forward of the mid chord length. The position of the internal stiffener was estimated to be $38 \%$ of the chord length. The stiffener was assumed to be a simple vertical plate, see Figure 8, running from the top of the hydrofoil down to the bend at the tip. The stiffener geometry and location are considered a large uncertainty in the current research as, in reality, most stiffeners normally present more complex shapes, e.g., a U, C, or box shaped, consisting of multiple parts and tapering in different locations along the span. 


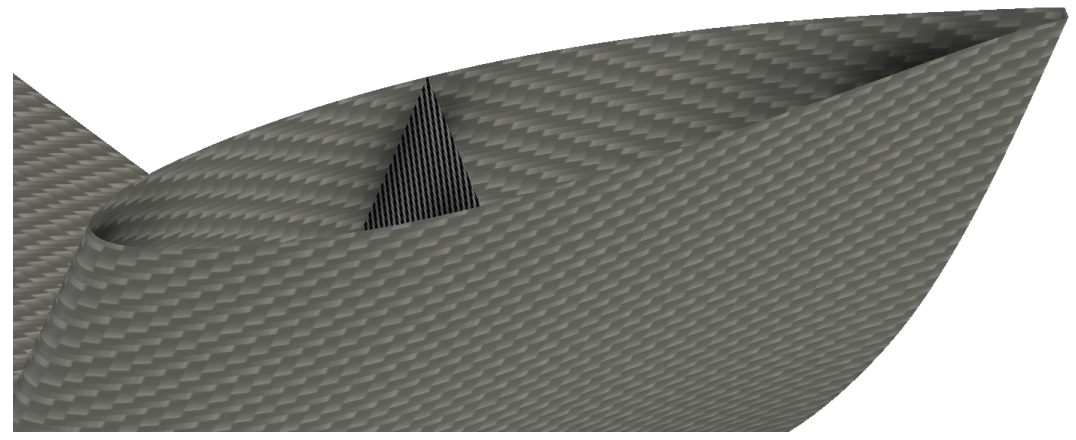

Figure 8. Estimation of the internal stiffener.

\section{Experimental Setup}

During the cavitation tunnel experiments, a Kempf and Remmers R-41 six component balance was used to measure the forces and moments acting on the NACRA 17 daggerboard. The components are calibrated to the ranges specified in Table 2 and present uncertainties for each force channel below $0.5 \%$ and below $1 \%$ for moment channels.

Table 2. Cavitation tunnel balance specifications.

\begin{tabular}{ccc}
\hline Component & Range & Uncertainty \\
\hline Fx & $1000 \mathrm{~N}$ & $4 \mathrm{~N}$ \\
$\mathrm{Fy}$ & $4000 \mathrm{~N}$ & $15 \mathrm{~N}$ \\
$\mathrm{Fz}$ & $4000 \mathrm{~N}$ & $15 \mathrm{~N}$ \\
$\mathrm{Mx}$ & $2000 \mathrm{Nm}$ & $4 \mathrm{Nm}$ \\
$\mathrm{My}$ & $200 \mathrm{Nm}$ & $2 \mathrm{Nm}$ \\
$\mathrm{Mz}$ & $500 \mathrm{Nm}$ & $5 \mathrm{Nm}$ \\
$\mathrm{Ry}$ & $360^{\circ}$ & $0.5^{\circ}$ \\
$\mathrm{Rz}$ & $15^{\circ}$ & $0.5^{\circ}$ \\
\hline
\end{tabular}

During the tests, the hydrodynamic forces and moments were measured with the balance and the structural deformation was recorded with stereo Digital Image Correlation (DIC). DIC has been used at a variety of scales from high magnification [15] to large-scale structures [16]. This technique involves the use of digital cameras that register a series of images of a surface on which a randomized speckle pattern is applied. The key advantage are the use of simple equipment, the fact that is a non-contact measurement technique, and its high-fidelity of precision [17]. Within the DIC software, in this case DaVis 10 Strain Master from LaVision, the speckle pattern is mapped to calculate the deformed shape, thereby allowing the derivation of the deflections and strains of the investigated object [18]. The use of two cameras, in a stereo configuration, allows for the measurement of deformations both in the plane normal to the camera and out of plane, i.e., 3D DIC. The current research builds from experimental techniques on FSI recorded during wind tunnel experiments [19-21] and adapts the technique for use in a cavitation tunnel configuration. Particular care was taken to ensure that the speckle pattern applied to the Z-Foil, using the black background color of the carbon with white speckles, had a distribution of randomized speckles in the area of interest that could ensure at least 6 pixels resolution per speckle, to avoid pixel locking and lack of data on the measurement surface. Furthermore, optical prisms were added between the lenses and the cavitation tunnel viewing windows to help reduce the diffraction angle increased by the water medium [22]. The addition of the prisms allowed the stereo angle to be reduced from $54^{\circ}$ to approximately $30^{\circ}$ within the fixed stand-off distances particular of cavitation tunnels. The arrangement of the equipment can be seen in Figure 9 and the specifications of the DIC setup can be found in Table 3. To ensure that the foil remains in focus during the experiments for the investigated ranges of 
rake and leeway angles, it was necessary to calculate the expected depth of field for the chosen lenses, as presented by [23]:

$$
D o F=D_{F}-D_{N}=\frac{2 f^{2} s^{2} N c_{b}}{f^{4}-s^{2} N^{2} c_{b}^{2}} .
$$

In Equation (1) $D_{F}$ is the distance from the camera to the far limit of the depth of field, $D_{N}$ is the distance to the near limit, $s$ is the specimen distance from the camera, $c_{b}$ is an assumed blur circle of 2 pixels, $f$ is the focal length, and $N$ the $f$-number [23]. For the DIC high-speed camera the depth of field was calculated to be $\approx 302 \mathrm{~mm}$ with a blur circle of 2 pixels and $602 \mathrm{~mm}$ with a blur circle of 4 pixels.

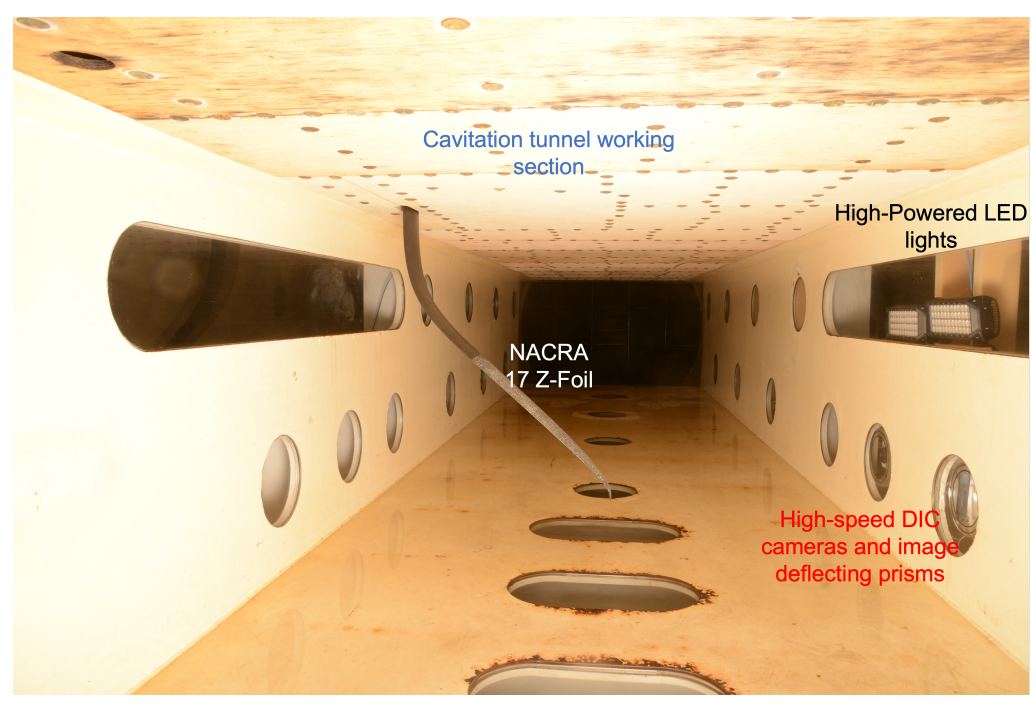

Figure 9. SSPA's cavitation tunnel test section with the NACRA 17 foil with speckle pattern applied to it. Two high powered LED lights are used as white light imaging from the oval side window. Two Phantom VEO 710L high-speed cameras are recording the foil displacement through prisms from the circular side windows.

Table 3. DIC performance table showing the equipment and the setting used.

\begin{tabular}{ll}
\hline Equipment & Set-Up \\
\hline & 2 high-speed Phantom VEO 710L \\
& Sensor size: $25.6 \times 16 \mathrm{~mm}$ \\
& Pixel size: $20 \mu \mathrm{m}$ \\
& Resolution $(\mathrm{max}): 1080 \times 800$ pixels \\
& Exposure time: $2000 \mu \mathrm{s}$ \\
& Frame rate: $0.5-2 \mathrm{kHz}$ \\
\hline \multirow{3}{*}{ Lens } & Nikon: Nikkor $50 \mathrm{~mm} \mathrm{f} / 1.8 \mathrm{D}$ \\
& Aperture: $f-8$ \\
& Depth of field: $302 \mathrm{~mm}$ \\
\hline \multirow{2}{*}{ Speckle pattern } & Speckle size: approx. 6 pixels \\
& Dimensions: $500 \times 180 \mathrm{~mm}$ \\
\hline \multirow{3}{*}{ Angles } & Prism angle: $-24^{\circ}$ \\
& Stereo angle: approx. $54^{\circ}$ \\
& Effective stereo angle: approx. $30^{\circ}$ \\
\hline \multirow{2}{*}{ DIC Processing } & Subset size: 29 pixel \\
& Step size: 9 pixel \\
\hline
\end{tabular}


Being a full-field measuring technique, DIC is able to capture the shape of $30-35 \%$ of the span of the Z-Foil. The investigation area was set near the tip of the daggerboard, as seen in Figure 3b,c. This setup was chosen to be able to detect the largest deflections. As shown in Figure 3c, the DIC system is calibrated to measure the $\mathrm{z}$-displacement normal to the surface of the foil, with positive $\mathrm{z}$-displacement when the foil is deflecting toward the cameras. Figure 10 shows the view of the two high speed cameras during calibration as well as the calibrated image created by overlaying the two camera views. The calibration, performed with LaVision 309-15 calibration plate, defines the location of the DIC coordinate system as well as the Root Mean Square (RMS) error values, which in this case are $<0.06 \mathrm{~mm}$. From Figure 10c it is possible to see how the cameras were placed to allow a larger field of view along the span of the foil.

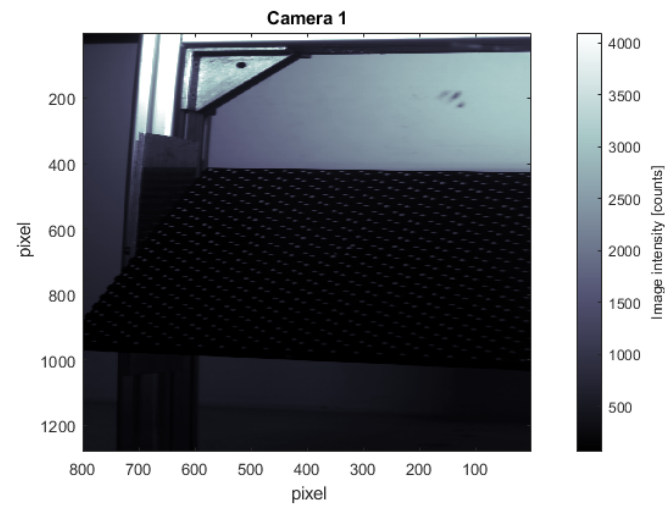

(a) View from Camera 1

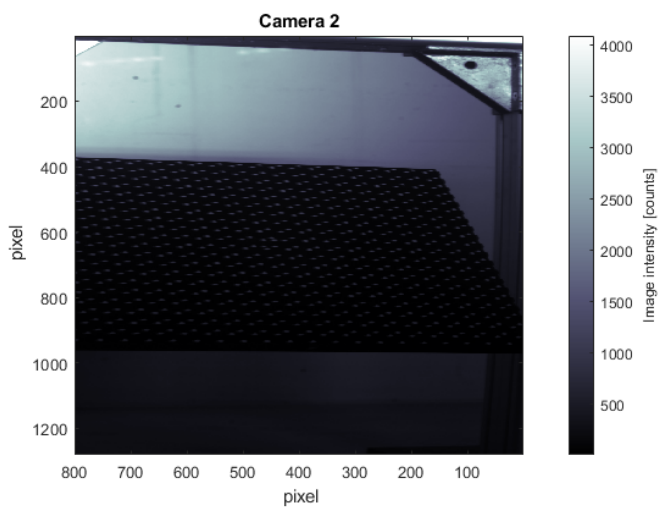

(b) View from Camera 2

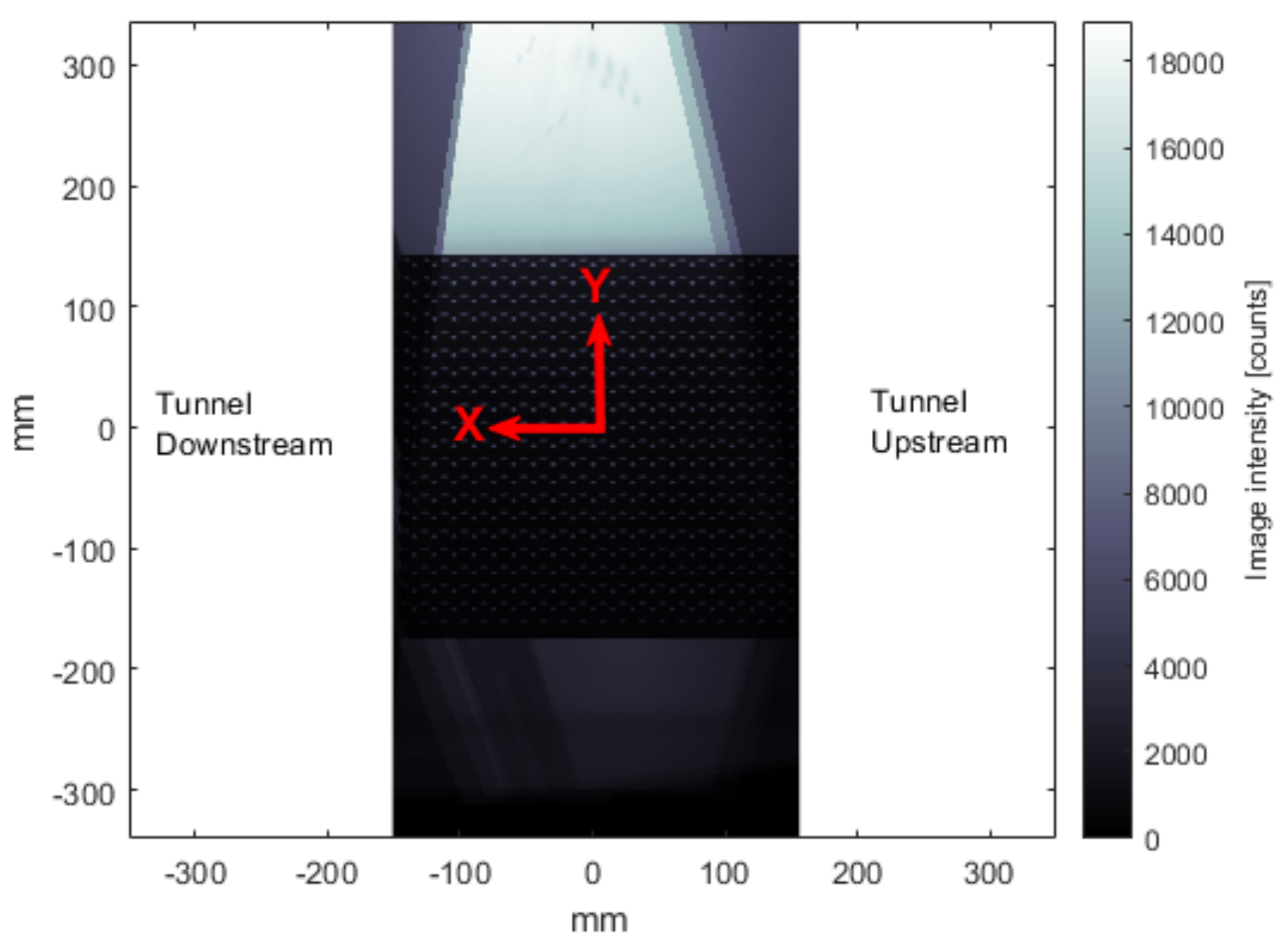

(c) Calibrated dewarped image

Figure 10. Calibration of the DIC system with view of the calibration plate from the two cameras and the final calibrated image with the coordinate system overlaid. 
Figure 11 presents the average static error in the system. Those values are not only extremely small compared to the expected deflection, but are more importantly randomly distributed across the surface, ensuring a good level of accuracy in the DIC system.

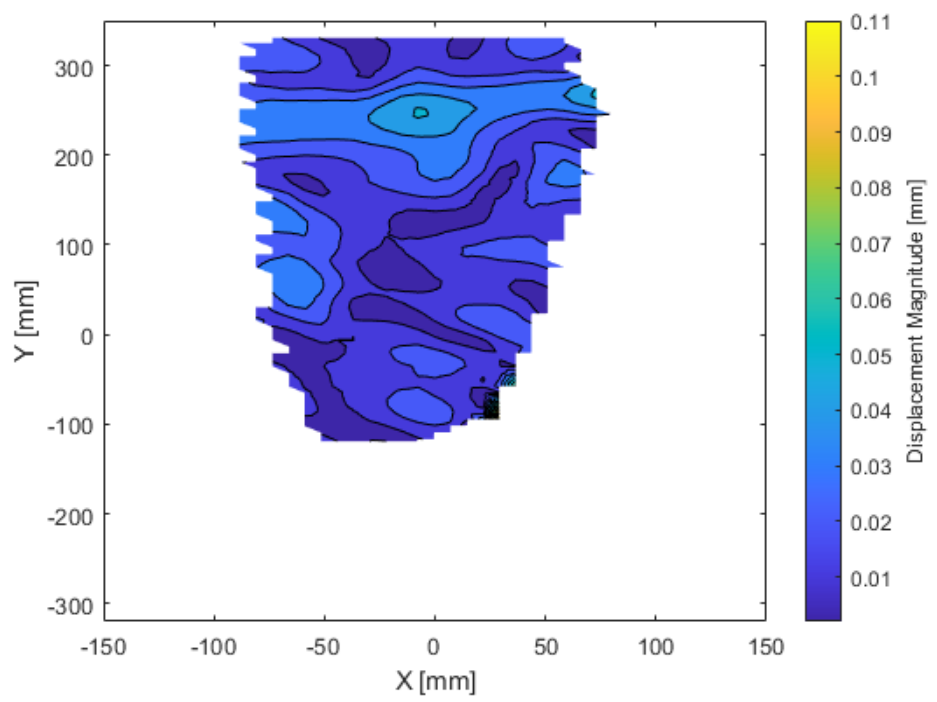

Figure 11. Average static error in the DIC system.

An example of displacement of the Z-foil overlaid over the speckle pattern from $\mathrm{DaVis}$ can be seen in Figure 12. The leading edge is on the right-hand side of the figure.
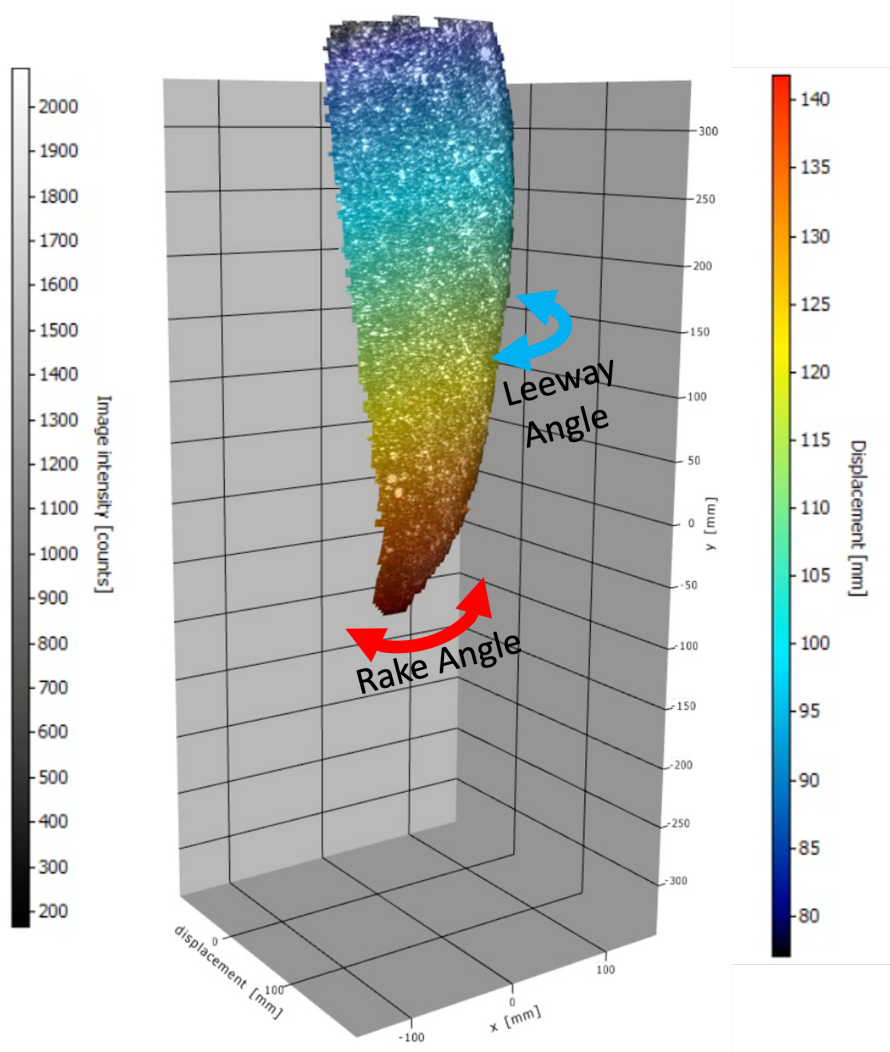

Figure 12. NACRA 17 Z-Foil tip section deflection as measured from the stereo-DIC configuration. The rainbow color-map specifies the displacement magnitude. The gray-scale color-map specifies the intensity counts of the randomized speckles applied with paint on the surface of the Z-Foil as seen from the DIC cameras. 


\section{Computational Methods}

As mentioned earlier, since composite hydrofoils show a considerable deflection and twist under different loading conditions, a two-way coupling approach is employed in the current study. A generic solution algorithm for a two-way coupling routine is shown in Figure 13.

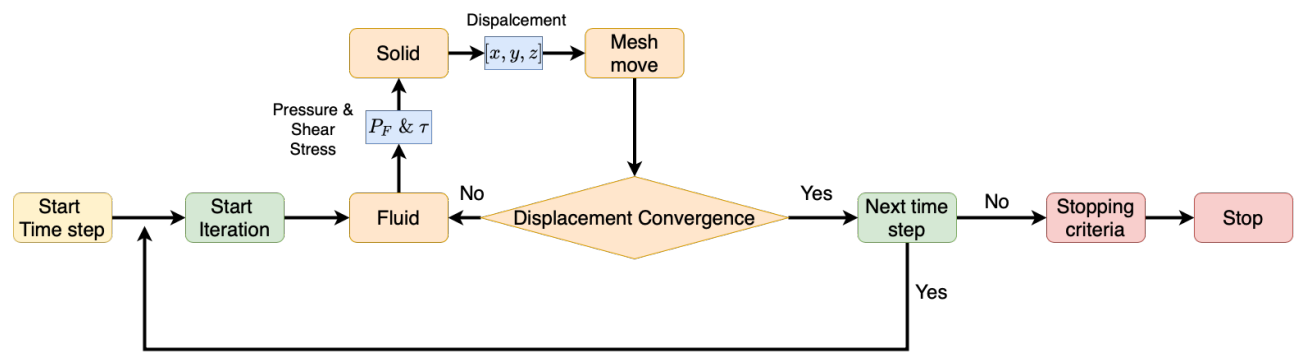

Figure 13. Fluid-Structure Interaction coupling routine where the dynamics of the flow is described using Computational Fluid Dynamic (CFD) and the Solid is characterized using Finite Element Analysis (FEA).

Two different numerical methods have to run together for calculating the deflection of the foil. The first one is a Computational Fluid Dynamics (CFD) solver for obtaining the pressure and shear stresses acting on the surface of the foil due to the water flow around the foil, and the second one is a Finite Element Analysis (FEA) solver for structural analysis of the foil under the aforementioned stresses.

The FEA model is created using ABAQUS. The reason for choosing this commercial FEA solver is its capability of coupling with Star-CCM+, a CFD solver, for FSI simulations. In the co-simulations, the structural analysis of the hydrofoil (structural computational domain) is carried out in ABAQUS, and STAR-CCM+2021.1 solves the Navier-Stokes equations for the flow around the hydrofoil (flow computational domain). The two domains are interconnected using the SIMULIA Co-Simulation Engine (CSE). The co-simulation between ABAQUS and Star-CCM+ permits the creation of an interaction between the two domains through a common physical interface surface, in this case the surface of the Z-foil subject to fluid loading. The interface conditions are the compatibility of the kinematics and traction at the fluid-structure interface. The structural domain is in motion and its motion follows the material properties defined within the FEA solver and under investigation in this research. On the interface surface the data are mapped from the fluid solver to the structural solver and vice-versa.

Running a co-simulation consists of a sequence of actions that iterate between the FEA and CFD codes. The motion, pressure, and shear forces of the flow obtained from STAR-CCM+ will cause the solid to deflect in ABAQUS; as a result, the structure deflection influences flow features. The described process runs during one-time step (100 inner iterations) until a converged solution for the displacement of the structure is obtained. The simulation then carries on to the next time step. The process is repeated until a fully converged solution is obtained. In case of the relatively stiff structure, a converged solution is found when the maximum displacement is reached. However, for more flexible structures or in case of flutter, the structure and the flow may show an oscillatory behavior over time.

Since the hydrofoil geometry deflects under different loading over time, a mesh morphing algorithm is utilized to redistribute the mesh vertices in response to the displacement of the boundaries. The initial movement that the morpher imposes on the grid is defined through a set of control points, which originate from the mesh vertices on the foil surface. Then, an interpolation field is constructed by the mesh morpher by using these displacements, which is eventually used for calculation of the displacements of all mesh vertices.

Each of the FEA and CFD solvers require separate computational setups and grids. The details of the setups for these two solvers are presented in Sections 5.1 and 5.2, respectively. 


\subsection{Finite Element Analysis}

In order to reverse engineer the material properties and to understand the bending and torsional stiffness of the Z-foil, the FEA model is initially compared to static load tests and a mesh convergence study is carried out comparing the numerical results with the known displacements, as measured with DIC. In the static test, a wooden beam is secured with two C-clamps and a pair of closed-cell foam blocks at half the length of the diagonal part of the hydrofoil. The wooden beam also serves as a cantilever, allowing a torsional moment to be applied by placing weights in front of the leading edge and behind the trailing edge, as seen in Figure 14. The weights are also applied centered along the chord length. The test matrix for the static test is presented in Table 4.

Table 4. Test matrix for static test load test.

\begin{tabular}{ccccccc}
\hline Position & \multicolumn{7}{c}{ Loads [kg] } \\
\hline $165 \mathrm{~mm}$ behind trailing edge & 5 & 10 & 15 & 20 & - & - \\
Centered & 5 & 10 & 15 & 20 & 25 & 30 \\
$195 \mathrm{~mm}$ in front of leading edge & 5 & 10 & 15 & 20 & - & - \\
\hline
\end{tabular}

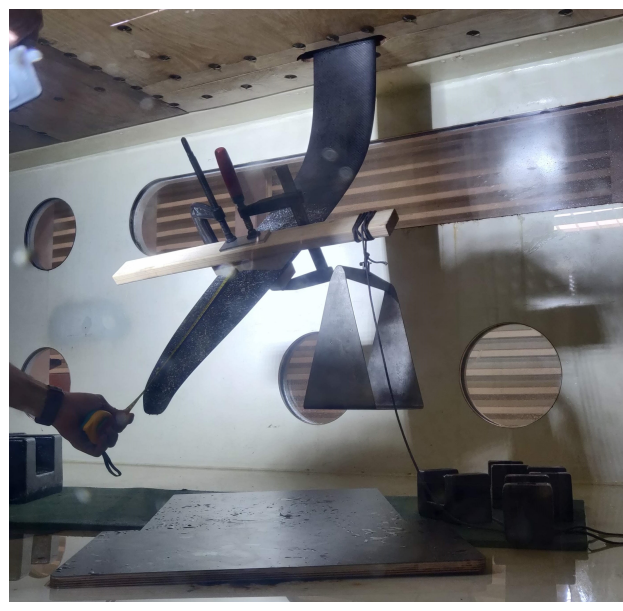

(a) Placement of test load at leading edge

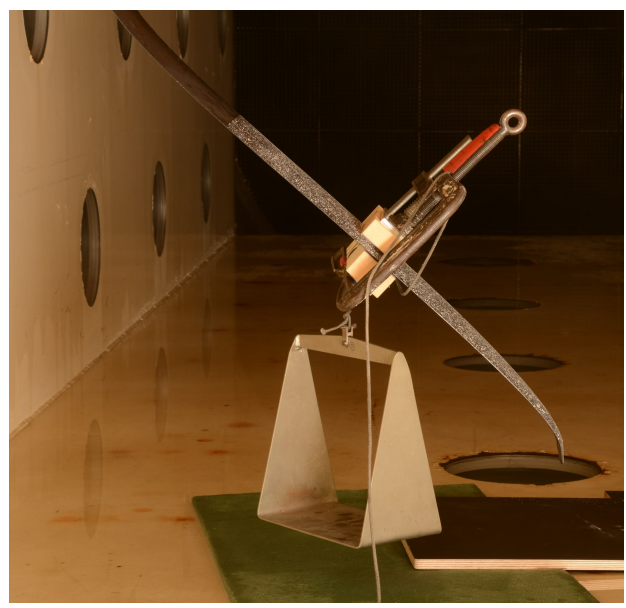

(b) Placement of test load at mid-chord

Figure 14. Placement of weights during static load test inside the cavitation tunnel test section.

The boundary conditions are set to replicate the real-life boundary condition of the NACRA 17 hull inside the foil-case with a fixed rotation and translation at the root and $500 \mathrm{~mm}$ below the root, see Figure 15. The boundary conditions are set, where BC1 is fixed in $x$ and $y$ translation and rotation around $x$ and $z$, and $\mathrm{BC} 2$ and BC 3 , at the root of the foil, fix in $x, y$ and $z$ translation and in rotations around $x$ and $z$. For the mesh convergence study, the mesh size of the FEA shell elements is varied from $16 \mathrm{~mm}$, down to $1 \mathrm{~mm}$ and the displacement and stresses in the hydrofoil are then compared for the different mesh sizes along a span-wise probed line, see Figure 15. The model can be assumed to be mesh independent in case the deflection and the stress levels do not change with further mesh refinement.

The model in ABAQUS is set up using conventional shell elements with four integration points. The use of shell elements is primarily related to the unknown thickness of the composite plies and overall stack of the foil. The selected shell elements are considerably less expensive in terms of computational cost compared to solid elements, which becomes an important factor in a FSI simulation where the solver needs to solve the problem and internal iterations thousands of times. 


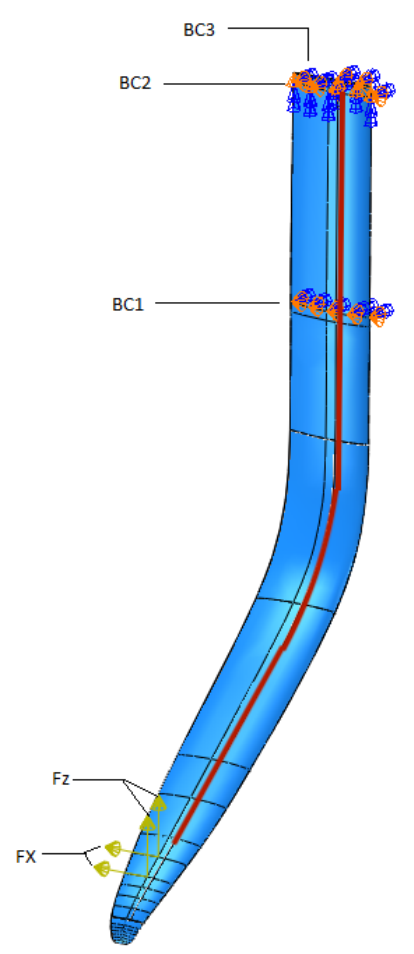

Figure 15. Boundary conditions at the root and $500 \mathrm{~mm}$ below the root and example location of applied $F_{X}$ and $F_{Z}$ forces. In red the location of the probed line from which the displacement and stresses are extracted.

The deflection and principal stress as extracted from the probed line, are shown in Figures 16 and 17. As can be seen in Figure 16, the numerical model does not present a variation in displacement with change in element size, however, the principal stress varies with mesh size, especially around $60 \%$ of the probed line location. In that region, a small variation of stress, leading to converged solutions, can be found with meshes finer than 4-6 mm, where the peak stress is well captured, as well as its path.

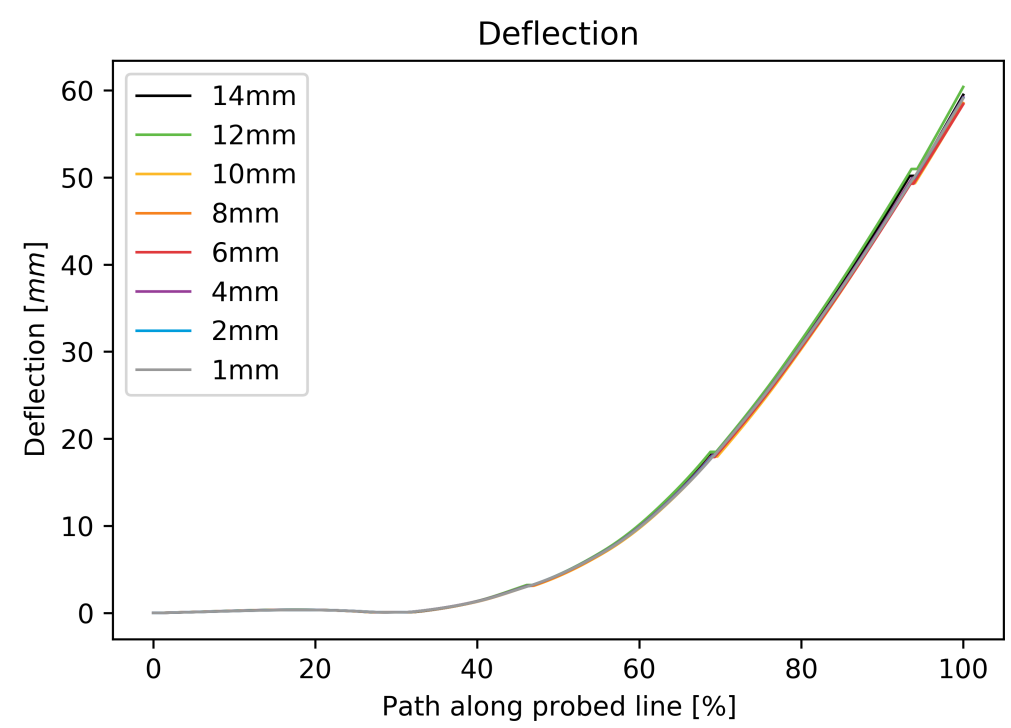

Figure 16. Convergence for displacement. 


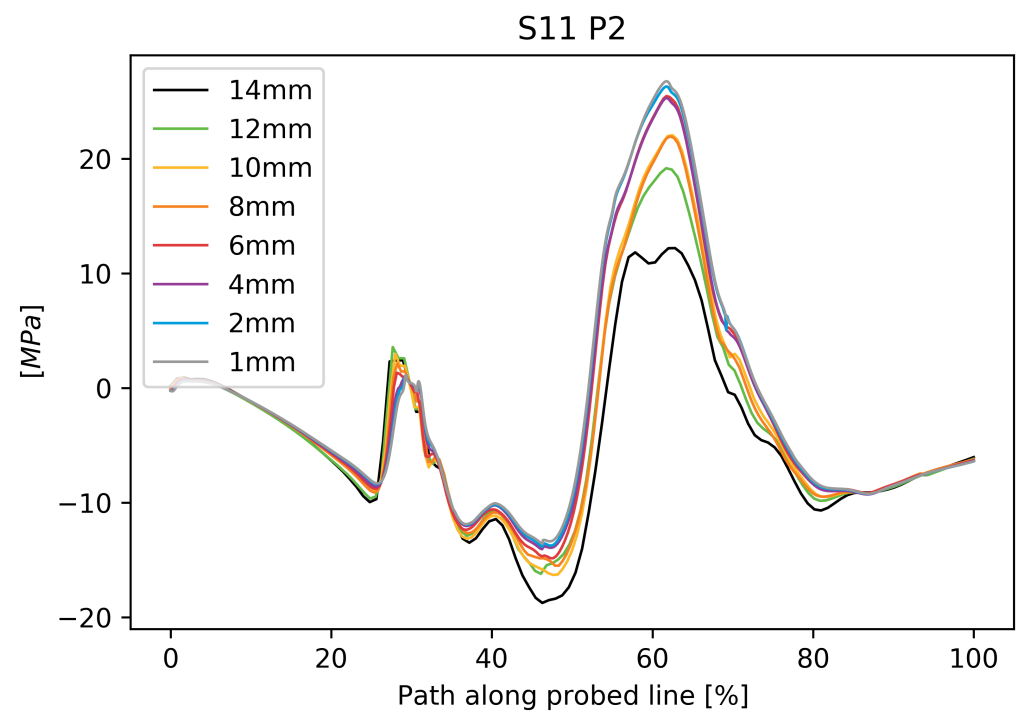

Figure 17. Convergence of first principle stress.

Investigating the static load cases in an area that spans $70 \mathrm{~mm}$ of span and the whole chord of the foil, the resultant numerical deflection obtained for a range of assumed material thickness and properties is compared against the DIC measured deflection data. The shell thickness of the overall laminate is set to $2.5 \mathrm{~mm}$, and the Young's modulus is changed until a close match with the experimental results is achieved. Figure 18 shows the difference between the experimental and numerical results with a Young's module of $55 \mathrm{GPa}$ and a $20 \mathrm{~kg}$ load placed at the center position. A decent match between the measured and the computed displacement is observed in this figure, however, the agreement is reduced close to the leading edge, on the right hand side of the contour plot. Further investigations are therefore needed to accurately assess the torsional modulus $G$ and/or the position and shape of the internal stiffener.

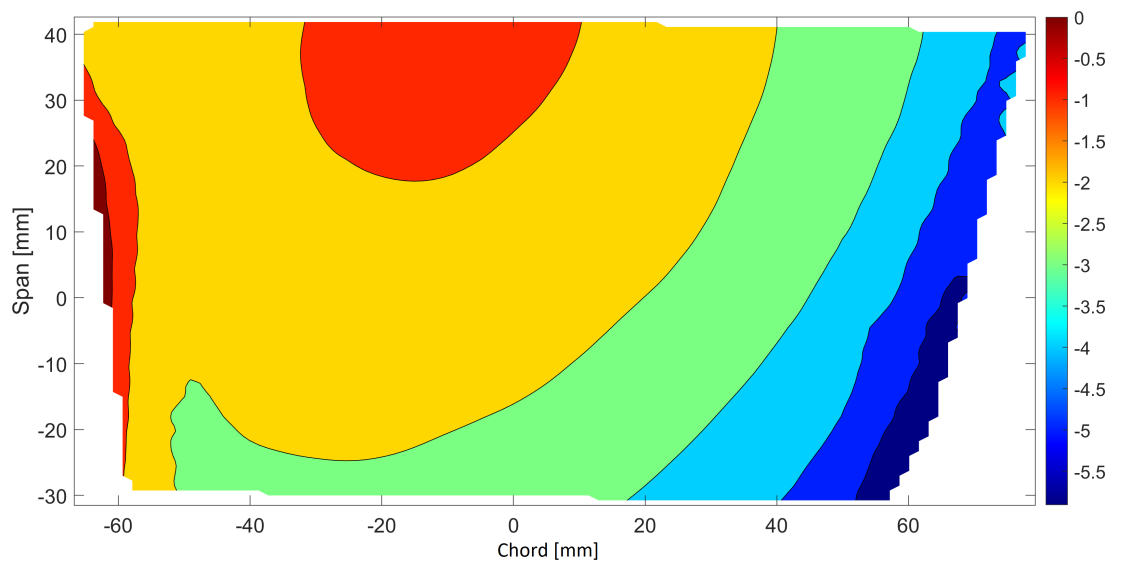

Figure 18. Difference between the measured and simulated numerical deflections for the static load case in millimeter.

\subsection{Computational Fluid Dynamics}

The geometry of the computational domain is created based on the actual cavitation tunnel of SSPA, where the experiments were carried out. The numerical simulations are carried out with the code STAR-CCM+2021.1. A Finite Volume method together with an unstructured grid consisting of trimmed cells (predominant hexahedral cells) along with prism layers for capturing the boundary layer is used for calculating the unsteady mass and momentum conservation equations in integral form. Different surface and volumetric mesh refinement regions are introduced to capture the geometry of the foil and the flow 
structures with higher accuracy. An implicit unsteady time stepping scheme is utilized for temporal discretization. This scheme allows a wider stability range (Courant number larger than 1) and therefore large time steps. The k- $\omega$ turbulence model with wall functions is used to solve the turbulence effect on the mean flow. This system of equations is solved using a segregated iterative solution method based on the SIMPLE-algorithm. Details on discretization and solution methods can be found in [24-26]. The details of the mesh and the computational setup are given in Table 5. The resultant mesh can be seen in Figures 19-21.

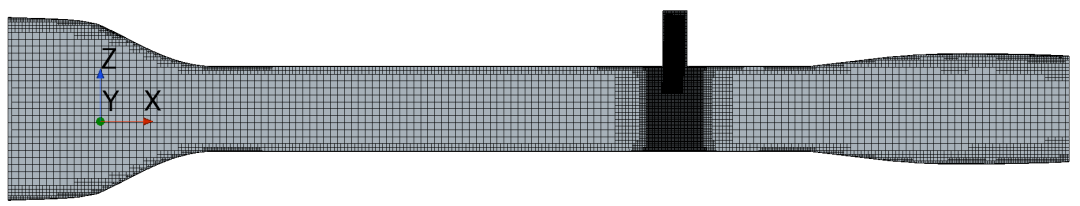

Figure 19. The structure of the mesh for the whole cavitation tunnel domain illustrating the refinement zones near the foil.

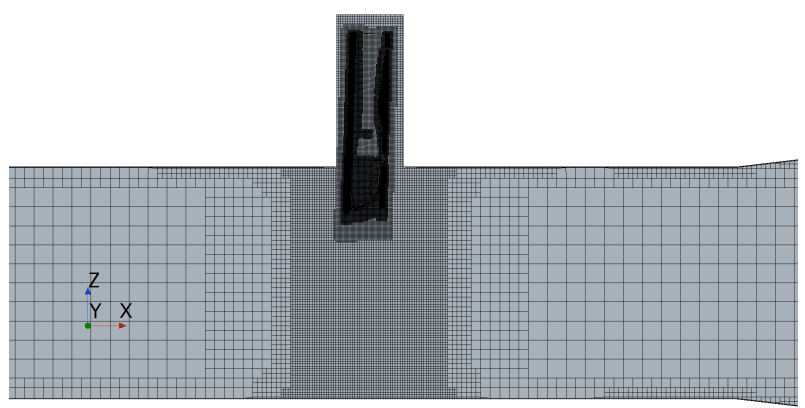

Figure 20. The structure of the mesh at a the foil region.

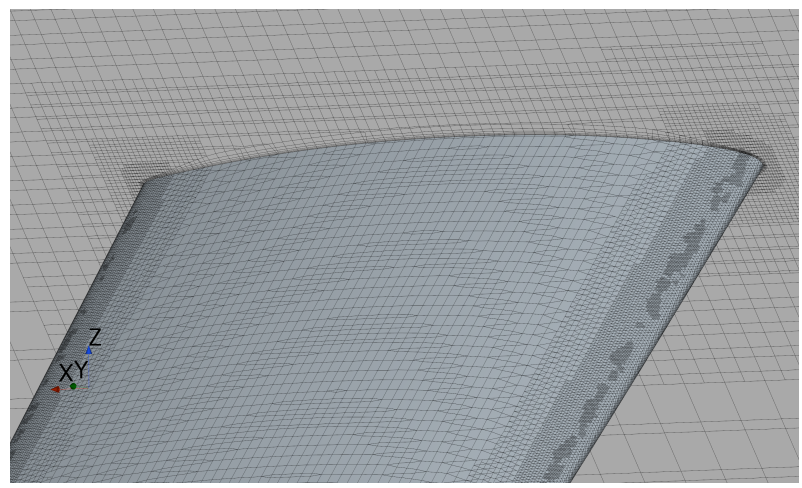

Figure 21. The structure of the mesh around the Z-foil showing a plane intersecting the span where the refinement regions at the leading and trailing edges are shown, as well as the boundary layer mesh.

\section{Verification}

A grid convergence study is performed for obtaining an adequate cell size for the computation and also obtaining the discretization uncertainty. This study includes seven grids, where the number of prism layers and the base cell size are varied systematically. Although the mesh is predominantly constructed of hexahedral cells, it has an unstructured topology (especially in the near-wall field). Therefore, the resultant of the systematic variations of the base cell size and the number of prism layers may not be an exact systematic grid variation where the grid topology remains unchanged. The coarsest grid has 7.1 million cells, and the finest grid size is 49.4 million cells. The lift and drag coefficients are calculated from Equation (2) for each of these grids.

$$
F_{x}=\frac{1}{2} C_{x} \rho V^{2} A
$$


In this equation, $F_{x}$ is the force in the foil-coordinate system e.g., lift and drag, $C_{x}$ is the force coefficient for these forces, $\rho$ is the water density $1000 \mathrm{~kg} \mathrm{~m}^{-} 3$, and $A$ is the foil area inside the fluid domain.

Table 5. Numerical settings.

\begin{tabular}{ll}
\hline Property & Mesh \\
\hline Cell type & Trimmed cell \\
\hline$Y^{+}$ & $30-50$ everywhere \\
\hline CL number & $<10$ \\
\hline Physics & Wall function \\
\hline & Around the foil \\
Surface refinement & Around the fluid domain \\
& Around the extruder at the top of the tunnel \\
& Around the foil part inside the extruder \\
\hline \multirow{3}{*}{ Volumetric refinement } & Around the foil \\
& Around the fluid domain \\
& Behind the foil tip \\
\hline Number of elements & 7.1 million cells \\
\hline & Inlet: $v_{\text {inlet }}=3.26 \mathrm{~m} / \mathrm{s}$, defined from \\
& $\mathrm{A}_{\text {inlet }} v_{\text {inlet }}=\mathrm{A}_{\text {foil }} v_{\text {foil }}$ to reach \\
Boundary conditions & a fully developed flow at the \\
& the foil Position of $9 \mathrm{~m} / \mathrm{s}$ \\
& Outlet: pressure outlet \\
& Top, bottom, Side, Wall: wall with \\
& no-slip conditions \\
\hline
\end{tabular}

A formal verification based on the Least Squares Root method by [27] is carried out. The convergence of lift and drag coefficients including their uncertainties are shown in Figures 22 and 23, respectively. The grid refinement ratio shown in these figures are obtained as the third root of the ratio of the total number of cells for the finest grid to the studied grid. The observed order of grid convergence, $\mathrm{p}$, is also given in these figures. The lift and drag coefficients obtained for all the studied grids are very similar to each other and therefore, with respect to the lower computational cost, the accuracy of the coarsest mesh with 7.1 million cells is deemed sufficient for this study. The numerical uncertainties for the lift and drag coefficients of this grid are $\mathrm{U}_{l}=6.2 \%$ and $\mathrm{U}_{d}=9.3 \%$, respectively.

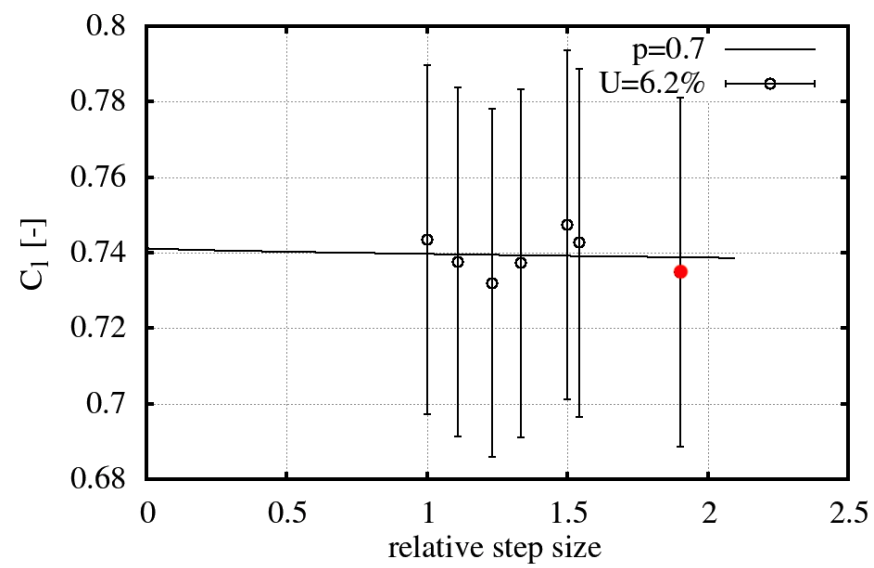

Figure 22. Convergence of the lift-coefficients. 


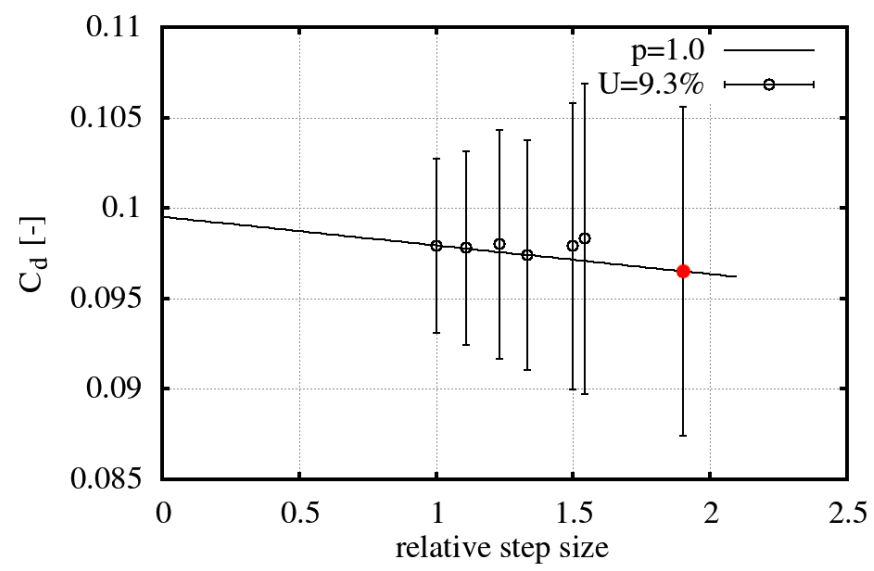

Figure 23. Convergence of the drag-coefficients.

\section{Discussion of the Results}

The results presented in this research contain both experimental and numerical methods. They are discussed individually and a comparison of the numerical model with the experimental results is also presented. The large deflections experienced by the Z-Foil under realistic foiling conditions make it necessary to discuss the implications on the overall boat and foil performance whilst sailing.

\subsection{Experimental Results}

The experimental campaign has focused on finding the correlation between the measured structural deformation and the monitored forces and moments to understand the FSI response of the NACRA 17 Z-foil. The maximum allowed leeway and rake angles are determined for each flow-speed by the maximum range of the 6-components balance. Particularly the $M_{x}$ measure is maximized when large leeway angles are set, affecting the change of leeway at the highest flow speeds.

Figures 24 and 25 present the z-displacement contour as measured by the DIC for a range of rake and leeway angles. From the figures, it is possible to see how the calibrated part of the foil, seen by the DIC cameras, changes when the rake angle varies, but ensuring that the tip is always in the field of view.

Figure 26 shows the $\mathrm{z}$-displacement averaged over an area across the chord and with span-wise location (i.e., y-location) between $-50 \mathrm{~mm}$ and $50 \mathrm{~mm}$, around the calibration center. Considering the schematics presented in Figure 4, the foil, in a sailing scenario, should always experience a deflection with the diagonal part of the foil moving toward the center-line of the catamaran, and effectively increasing the vertical lift $\left(-F_{Z}, L\right)$. When the rake and leeway angles are zero degrees, the foil experiences a positive $z$-deflection. The maximum deflection measured at the tip of the foil for flow speed of $9 \mathrm{~m} / \mathrm{s}$ is $\delta=260 \mathrm{~mm}$, corresponding to $24 \%$ of the immersed span.

Given the nature of a catamaran with two hulls and daggerboards, the two sides, depending on the applied rake, could present large differences in projected area, due to changes in deflection between the port and starboard side from the different loading conditions, bending and torsional stiffness, rake, and leeway angles differences.

Taking into consideration the FSI nature of foiling boats, an optimal rake should be chosen for the correct setups in closed, hauled, and downwind scenarios, once the leeway angle is known. Indeed, minimum tip deflection is desired in non-foiling close-hauled conditions, leading to larger side force generation; whereas a balance between side force and vertical lift is necessary in foiling scenarios.

The measured experimental forces are converted into lift $(L)$, drag $(D)$ and side force $(S F)$. The transformation matrix for leeway angle $(T)$ is referred as:

$$
D=F_{Y} \sin (T)-F_{X} \cos (T)
$$




$$
\begin{gathered}
S F=F_{Y} \cos (T)+F_{X} \sin (T) ; \\
L=-F_{Z} ;
\end{gathered}
$$

Figures $27-29$ show the lift and drag produced by the foil at 5,7 , and $9 \mathrm{~m} / \mathrm{s}$ respectively.

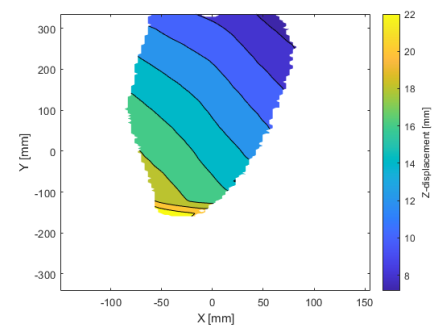

(a) Rake $-2^{\circ}$ Leeway $0^{\circ}$

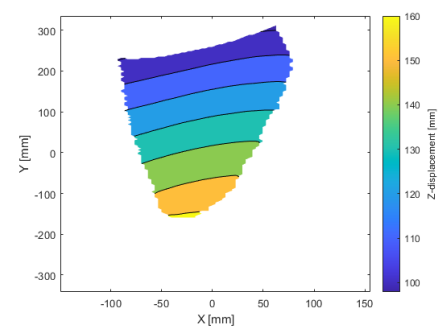

(d) Rake $1^{\circ}$ Leeway $0^{\circ}$

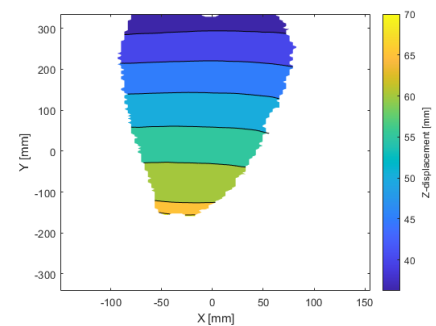

(b) Rake $-1^{\circ}$ Leeway $0^{\circ}$

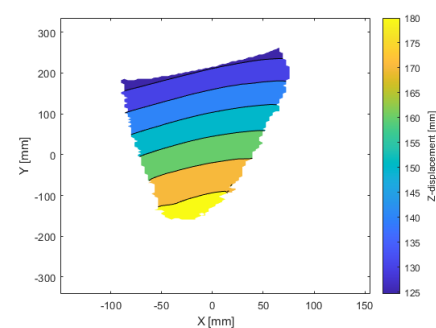

(e) Rake $1.5^{\circ}$ Leeway $0^{\circ}$

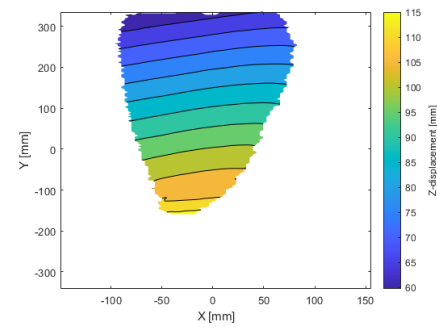

(c) Rake $0^{\circ}$ Leeway $0^{\circ}$

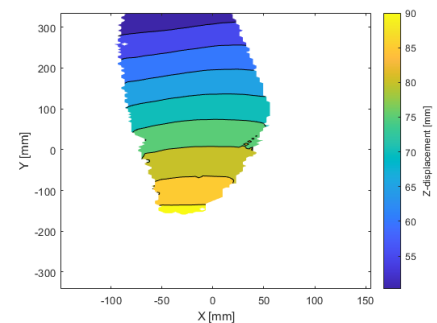

(f) Rake $2^{\circ}$ Leeway $0^{\circ}$

Figure 24. Change in z-deflection for a range of rake angles at a leeway of zero degrees at flow speed of $9 \mathrm{~m} / \mathrm{s}$.

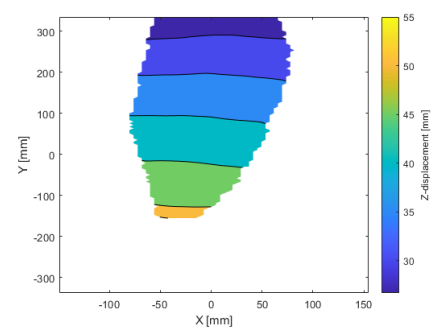

(a) Rake $-2^{\circ}$ Leeway $-1^{\circ}$

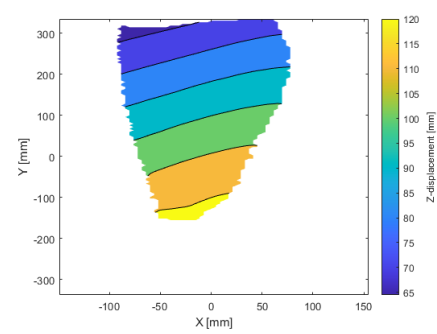

(d) Rake $1^{\circ}$ Leeway $-1^{\circ}$

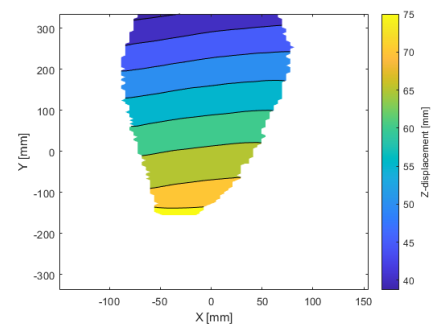

(b) Rake $-1^{\circ}$ Leeway $-1^{\circ}$

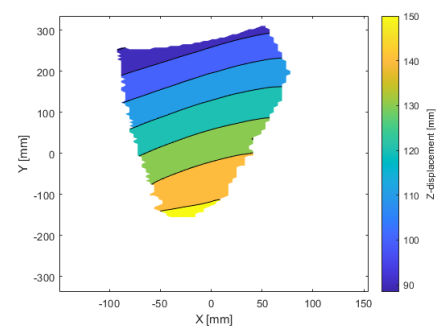

(e) Rake $2^{\circ}$ Leeway $-1^{\circ}$

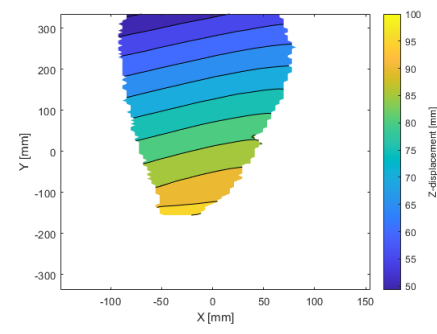

(c) Rake $0^{\circ}$ Leeway $-1^{\circ}$

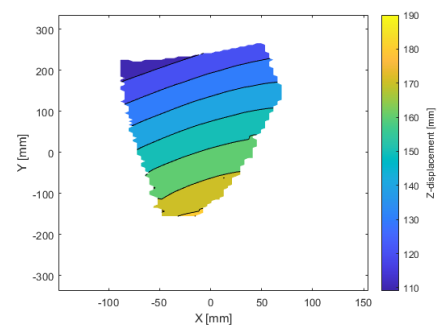

(f) Rake $3^{\circ}$ Leeway $-1^{\circ}$

Figure 25. Change in z-deflection for a range of rake angles at a leeway of -1 degrees at flow speed of $7 \mathrm{~m} / \mathrm{s}$.

Given the highly cambered section profile, minimum drag occurs at different combinations of leeway angles, away from zero, with a similar distribution for the three speeds, whereas the lift and side force distributions can be more linearly correlated to leeway and rake angle changes. The quadratic trend of $\mathrm{D}$ leads to the necessity of choosing a trade-off between low drag setups and maximum lift. Different configurations of rake for the windward and leeward foils could be set to minimize the overall drag, also named the 
differential angle. Indeed, the leeward foil is subject to a smaller leeway angle due to the toe-out arrangement. For a sailing, a leeway angle of $T=2^{\circ}, 2.5^{\circ}$, the leeway angle to which the leeward foil is subject, varies between $T=1^{\circ}$ and $T=1.5^{\circ}$, contrarily the windward foil, which varies between $T=-2^{\circ}$ and $T=-2.5^{\circ}$. To obtain minimum drag from the two $Z$-foils, the rake can be set to negative for the windward foil and to positive for leeward foil, $R=-2^{\circ}$ and $R=2 ; 2.5^{\circ}$, respectively. The differential configuration would indeed affect the righting moment $M_{Y}$, leading to a range of different crew weight possibilities.

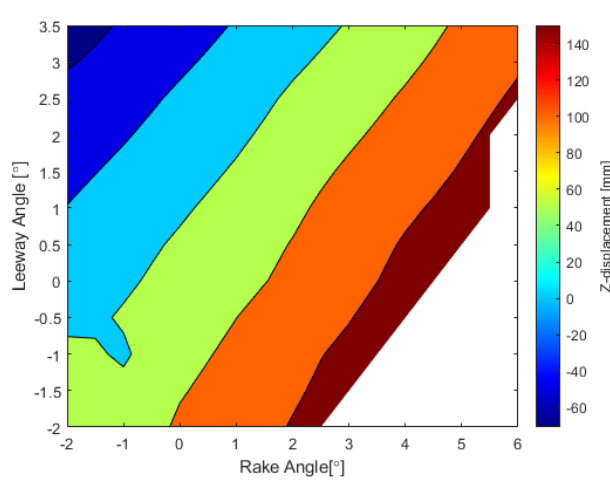

(a) Flow speed $7 \mathrm{~m} / \mathrm{s}$

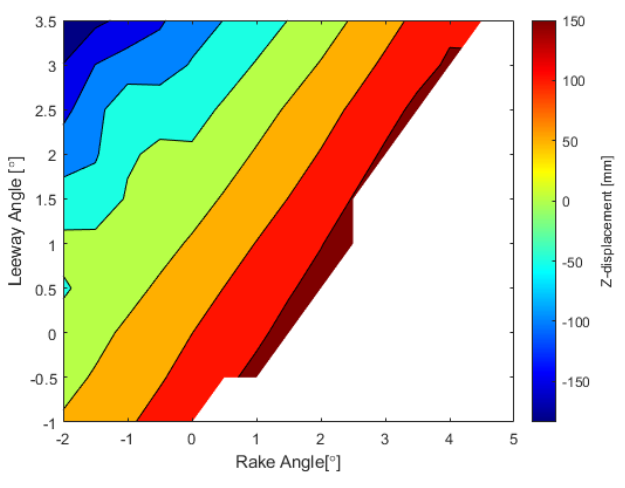

(b) Flow speed $9 \mathrm{~m} / \mathrm{s}$

Figure 26. Averaged $\mathrm{z}$-displacement for the investigated ranges of leeway and rake angles at flow speeds of 7 and $9 \mathrm{~m} / \mathrm{s}$.

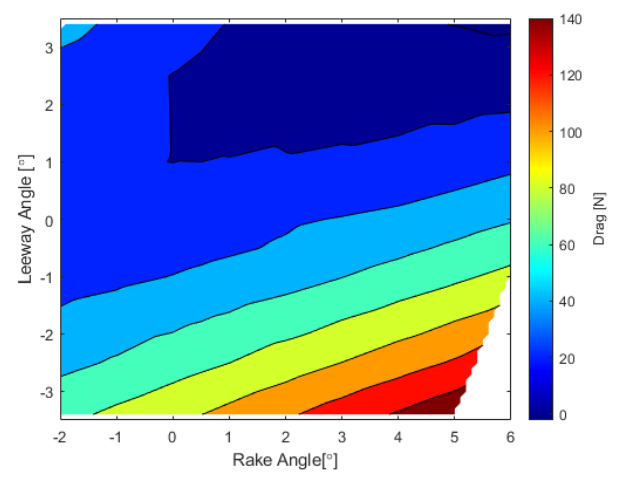

(a) Drag

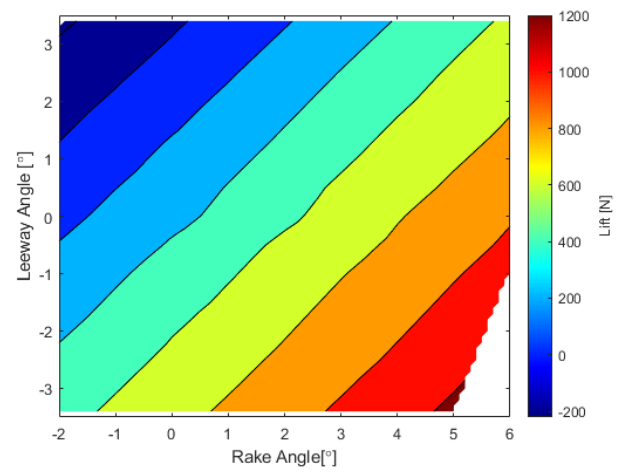

(b) Lift

Figure 27. Lift and drag for the investigated range of leeway and rake angles and flow speed of $5 \mathrm{~m} / \mathrm{s}$.

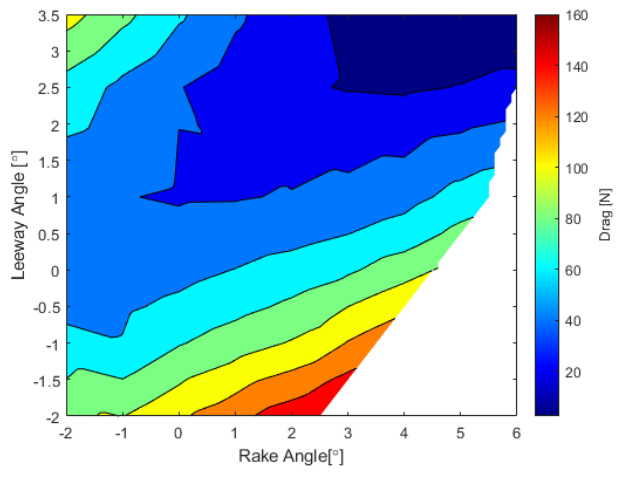

(a) Drag

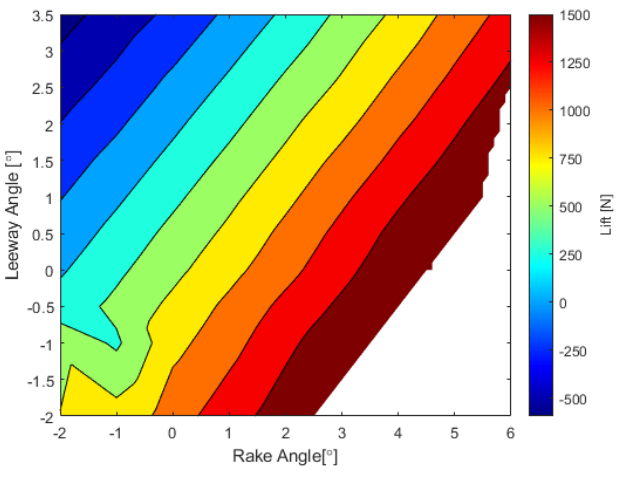

(b) Lift

Figure 28. Lift and drag for the investigated range of leeway and rake angles and flow speed of $7 \mathrm{~m} / \mathrm{s}$.

At the operating leeway angle ranges, it is possible to inspect the drag over lift profiles, as shown in Figure 30. The necessity of minimizing induced drag is not however only related to the desired lift or side force coefficient, but a minimum drag should be envisaged also in maneuvering scenarios, i.e., tacking, gybing, bearing away, and heading 
up, as described by [28]. Another important question to raise in a real environment, is the side force and lift distribution variations with ride height, connected to the possibility of minimizing induced drag. The range of drag values is heavily dependent on the applied rake. As the leeway angle would be changing with different meteorological and sailing conditions, the rake should be adjusted not only to aid foiling but also to minimize drag, considering both windward and leeward foils.

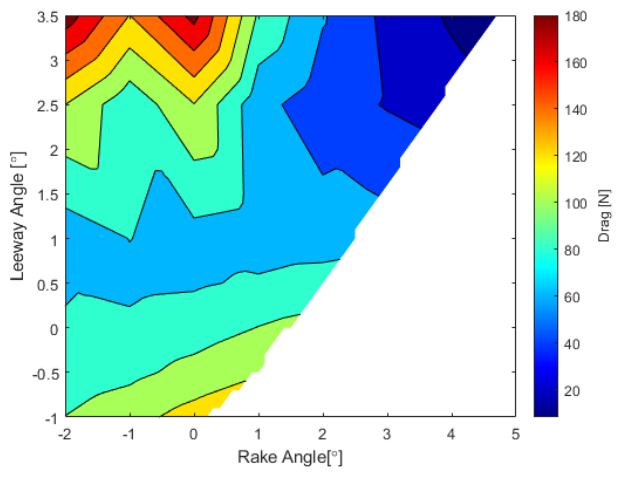

(a) Drag

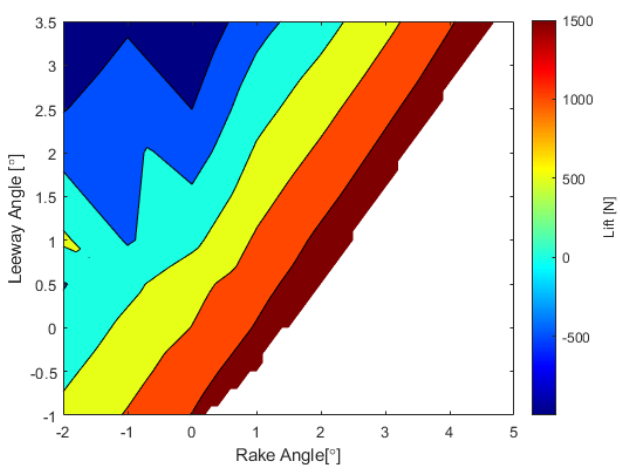

(b) Lift

Figure 29. Lift and drag for the investigated range of leeway and rake angles and flow speed of $9 \mathrm{~m} / \mathrm{s}$.

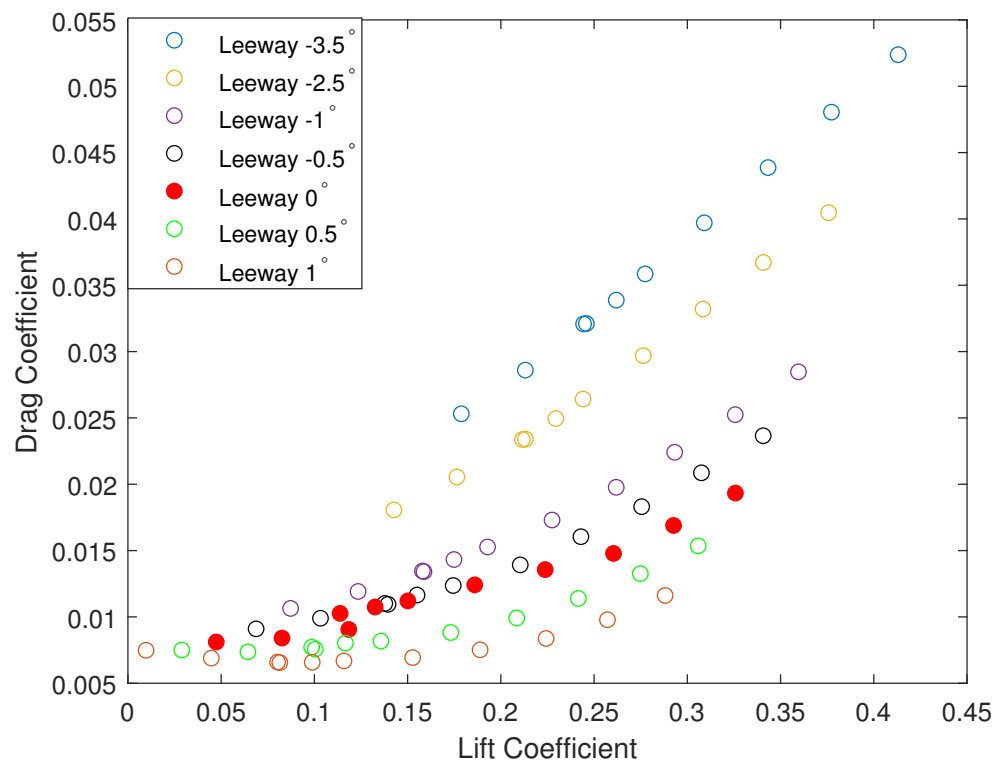

Figure 30. Drag coefficient over lift coefficient for the range of operating leeway angles at flow speed of $5 \mathrm{~m} / \mathrm{s}$.

\subsection{Numerical Results}

In this section, the results from the FSI simulations are compared with the data obtained from the measurements in the cavitation tunnel. Validation of the numerical FSI model enables the possibility of simulating untested conditions, such as different rake and leeway angels, flow velocity, or even different material properties. Such a computational model reduces the costs of developing and manufacturing a new hydrofoil. The quantities that are used for the validation study are lift and drag forces, as well as the displacement of the hydrofoil. Due to limitations on the computational resources, only a selected number of conditions from the test matrix are simulated. These selected conditions are specified in Table 6 in black. 
Table 6. Test matrix used in the experiments, the complete set shown in red and black, and in the numerical simulations, highlighted in black, at $9 \mathrm{~m} / \mathrm{s}$.

\begin{tabular}{cc}
\hline Leeway Angle (T) & Rake Angle (R) \\
\hline$-1^{\circ}$ & $0^{\circ}, 0.3^{\circ},-1^{\circ},-2^{\circ}$ \\
$-0.5^{\circ}$ & $0^{\circ}, 1^{\circ},-1^{\circ},-2^{\circ}$ \\
$0^{\circ}$ & $0^{\circ}, 1^{\circ}, 1.5^{\circ},-1^{\circ},-2^{\circ}$ \\
$0.5^{\circ}$ & $0^{\circ}, 1^{\circ}, 2^{\circ},-1^{\circ},-2^{\circ}$ \\
$1^{\circ}$ & $0^{\circ}, 1^{\circ}, 2^{\circ}, 2.5^{\circ},-1^{\circ},-2^{\circ}$ \\
$2.5^{\circ}$ & $0^{\circ}, 1^{\circ}, 2^{\circ}, 3^{\circ}, 3.75^{\circ},-1^{\circ},-2^{\circ}$ \\
$3.5^{\circ}$ & $0^{\circ}, 1^{\circ}, 2^{\circ}, 3^{\circ}, 4^{\circ}, 4.75^{\circ},-1^{\circ},-2^{\circ}$ \\
\hline
\end{tabular}

The time-averaged vertical lift and drag force obtained from the FSI computations are shown in Figures 31 and 32, respectively. The deviation of the computed lift and drag from the measured values are also shown in Figures 33 and 34, respectively. According to these results, the lift force is under-predicted and the drag force is over-predicted in the computations. The lift force is the minimum and very small (close to zero) at the largest leeway angles for all of the rake angles investigated (see Figure 31). Consequently, a minor under/over-prediction of the lift can result in a large comparative error, Figure 33. This is the main reason for the very large difference found between the computed and the measured lift around a leeway angle of $1^{\circ}$. Aside from this specific set, the comparative error of the lift force is below $15-20 \%$ for other combinations of rake and leeway angles at $9 \mathrm{~m} / \mathrm{s}$.

Despite the large variation of the lift force for the combinations of rake and leeway angles shown in Figure 33 the drag force variations are less severe (see Figure 32). This results in a more uniform comparative error for the computed drag, Figure 34. The average comparative error for the computed drag force is about $35 \%$ which is larger than that of the lift force. The drag force is one order of magnitude smaller than the lift force, leading to a larger comparative error for the computed drag relative to the computed lift. The largest error is found at a leeway angle of $2.5^{\circ}$ and the maximum investigated rake angles.

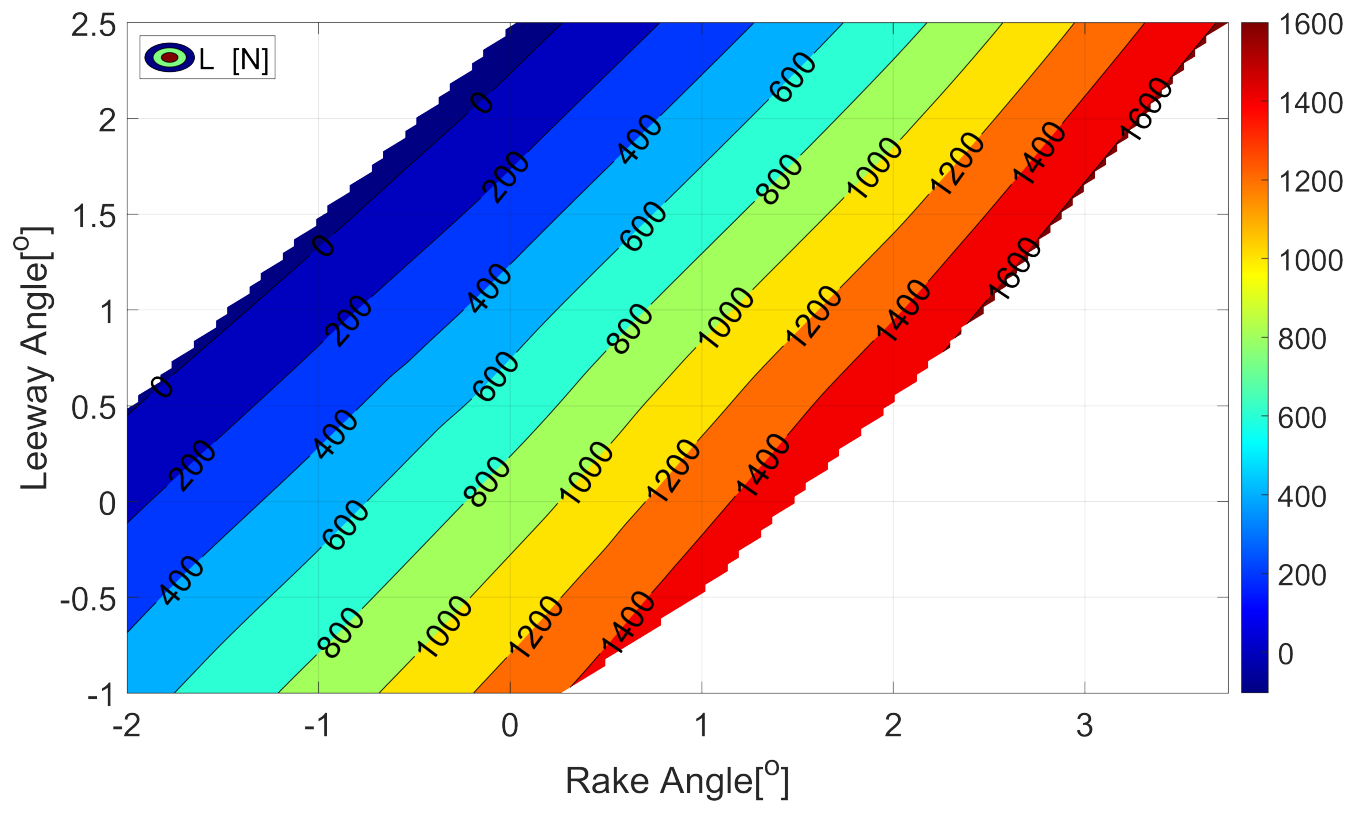

Figure 31. Computed lift force at $9 \mathrm{~m} / \mathrm{s}$, dimensions are in [N]. 


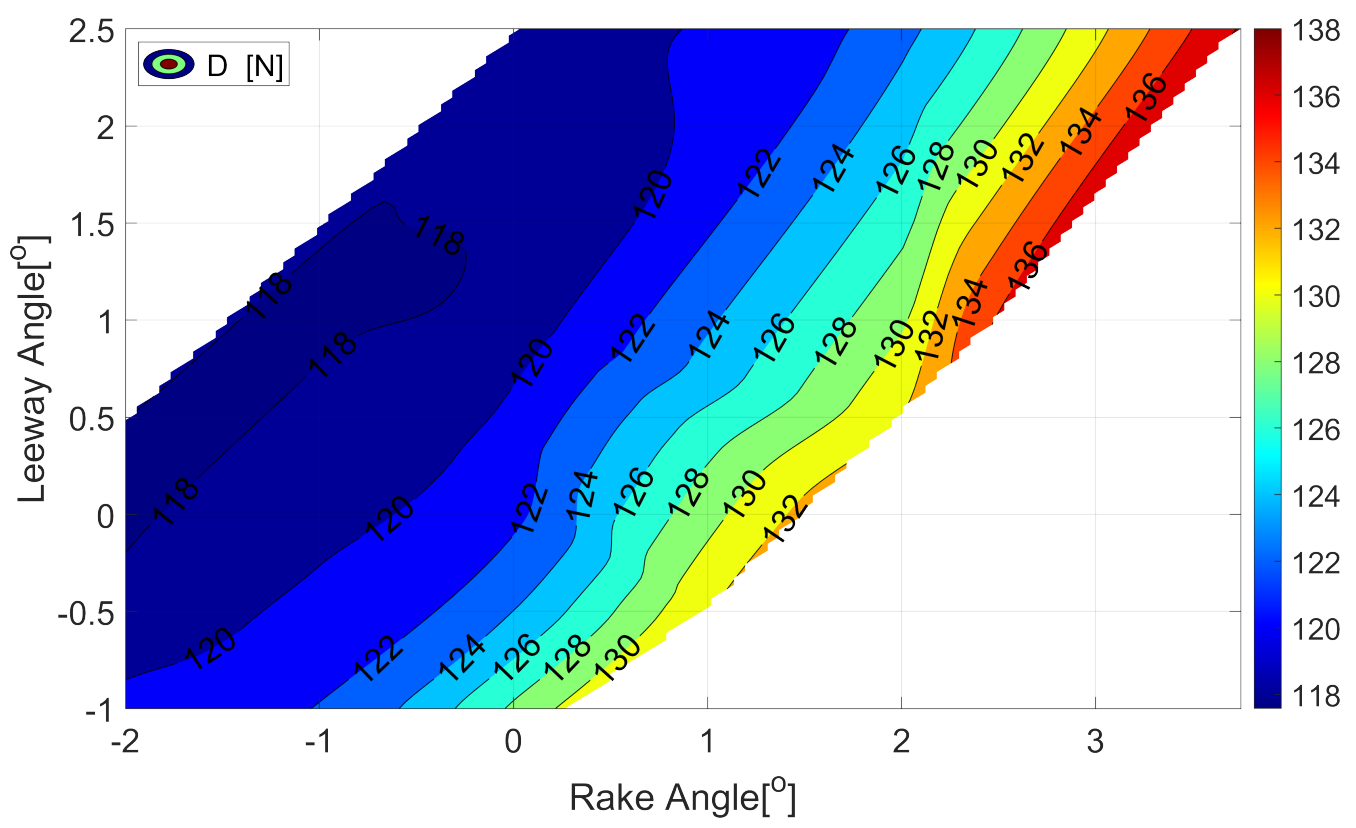

Figure 32. Computed drag force at $9 \mathrm{~m} / \mathrm{s}$, dimensions are in [N].

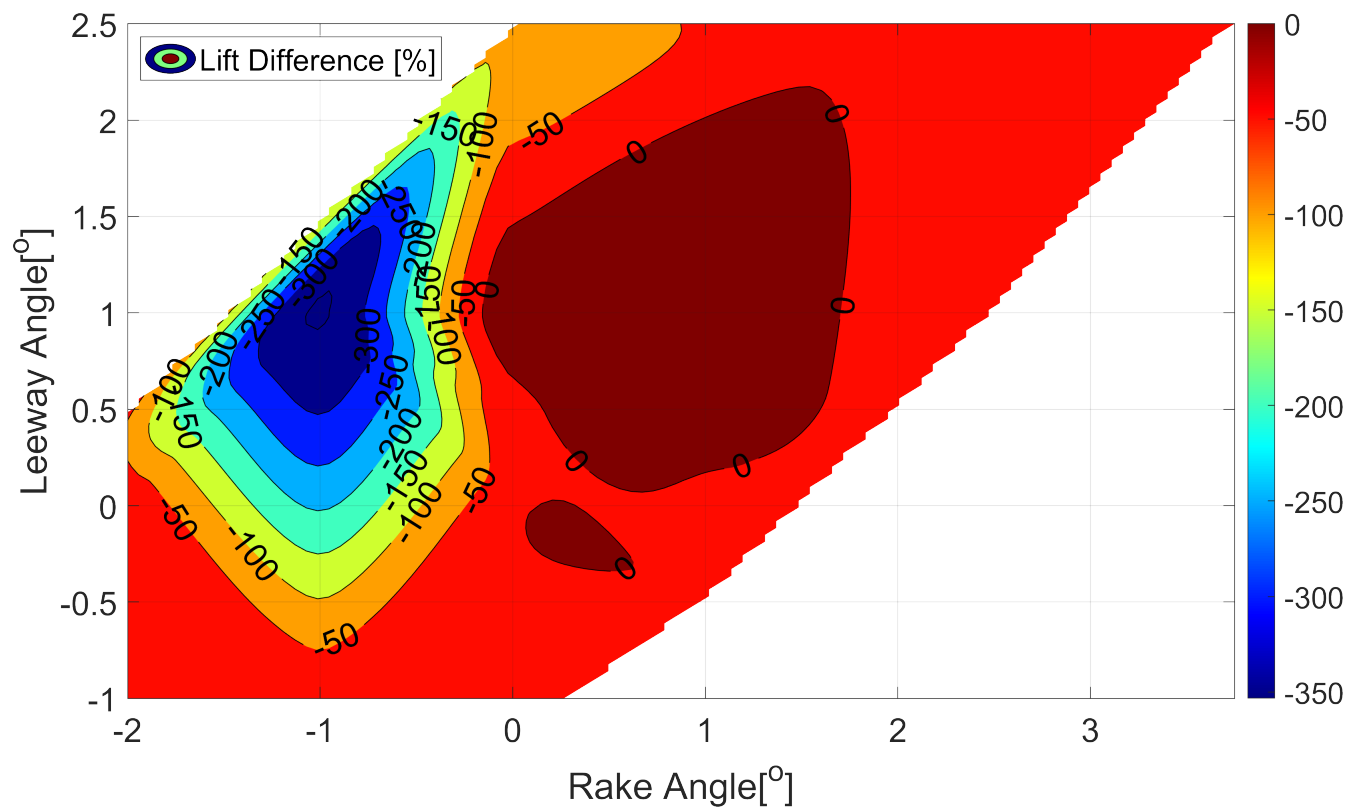

Figure 33. Difference between the computed and the measured lift force at $9 \mathrm{~m} / \mathrm{s}$, dimensions are in $\%$.

Figure 35, shows the computed and the measured displacement for one of the simulated configurations $\left(T=0^{\circ}\right.$ and $R=0^{\circ}$ ). The mean value of the displacement magnitude from the experiments is calculated from a set of point clouds obtained from the DIC measurements. All the DIC frames are combined into one point cloud and then a de-noise function from MATLAB Computer Vision Toolbox [29] is applied to the data set to remove any noise that might be present. A surface is then fitted to the filtered point cloud. The chord and span values represent the position on the foil surface close to the tip of the hydrofoil, and the $Z$ value is the final displacement magnitude in $\mathrm{mm}$. The chord-wise gradient of the displacement discrepancy in Figure 35a reveals that the foil experiences twist. The twist results in an altered angle of attack for the composite foil, effectively changing the leeway angle in the tip region. However, due to the simplification of the material properties into an isotropic material, the twist cannot be modeled in the computations. The estimated discrepancy in angle of attack is about $1.6^{\circ}$ for the case with $T=0^{\circ}$ and 
$R=0^{\circ}$. The comparison surface representation between the computed and the measured displacement for $T=0^{\circ}$ and $R=0^{\circ}$ at $9 \mathrm{~m} / \mathrm{s}$ is shown in Figure 35b.

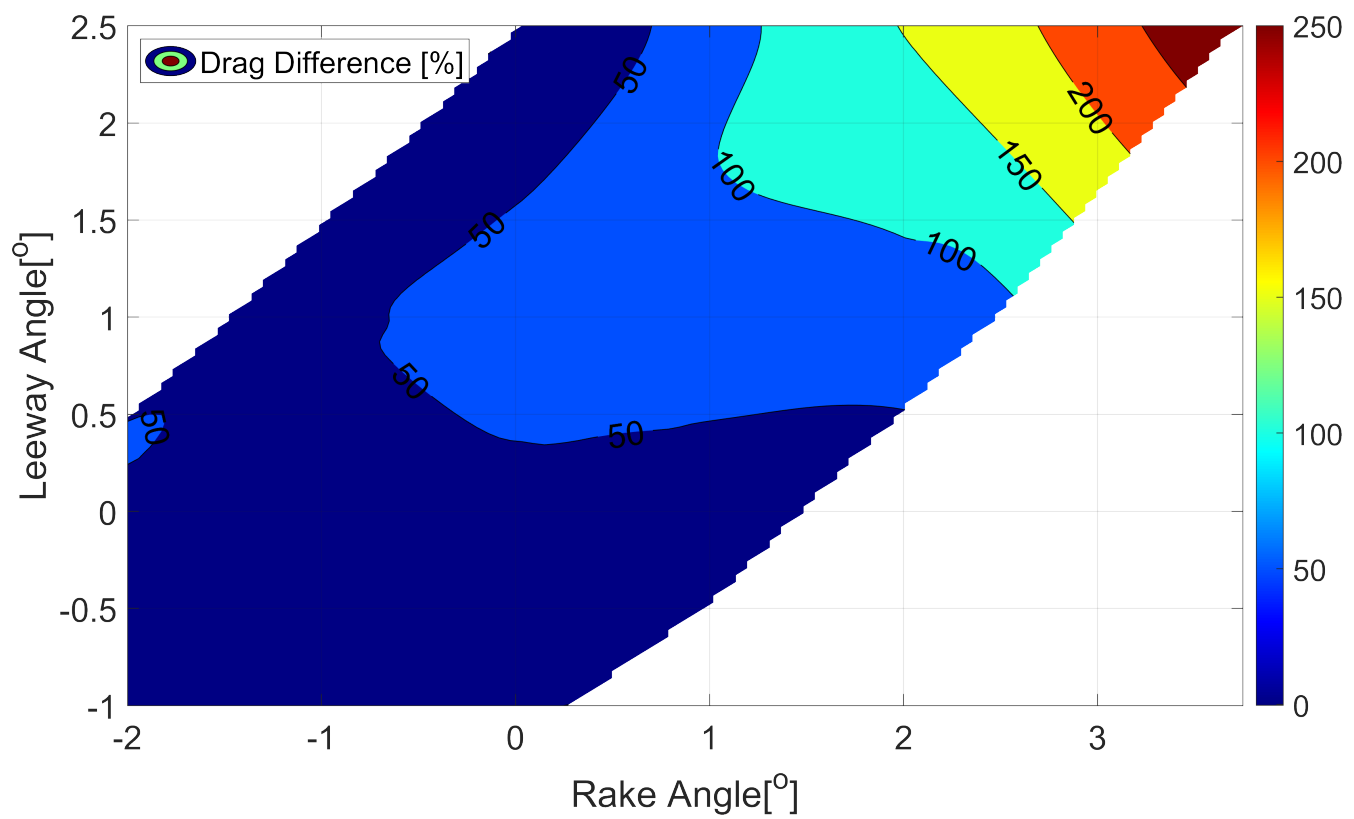

Figure 34. Difference between the computed and the measured drag force at $9 \mathrm{~m} / \mathrm{s}$, dimensions are in $\%$.

According to the results shown in Figure 35, the isotropic computational model used to represent the numerical Z-Foil is too stiff, which results in smaller displacement experienced from the numerical model, which in turn affects the lift force generation. Another discrepancy is found in the inability to capture the twist of the hydrofoil linked both to torsional modulus as well as stiffener location and tapering of the plies. If the isotropic model was able to capture the twist and thus the angle of attack, the forces exerted on the foil would have increased in the simulation, which possibly could have led to larger displacement, entailing the complexity of FSI problems.

With the aforementioned findings, a sensitivity study was carried out to understand the correlation between the hydrofoil stiffness and its deflection through variation of the Young's modulus in a series of one-way coupling simulations for the isotropic model. The Young's modulus was varied between 30 to $52 \mathrm{GPa}$ in steps of $2 \mathrm{GPa}$, resulting in eight different configurations. The average displacement in an area close to the tip is then computed and compared with the average displacement in the same area from the experimental results. Four of these configurations are shown in Figure 36. The figure indicates a large dependency between the hydrofoil displacement and the Young's modulus of the material. Although some of the employed stiffness show a better agreement with the experimental displacement (e.g., E = $44 \mathrm{GPa}$ ), one single Young's modulus cannot correctly represent the structural response of the hydrofoil for all the combinations of rake and leeway angles. These result may also indicate the inaccuracy of the hydrofoil's internal structure in the numerical model and the dependency on torsional modulus.

The main difference between the numerical and the experimental results can be related to the use of reversed engineering material properties for the foil used to preform the simulations in the computations. The properties were identified through a series of static load tests, however it should be noted that the uncertainty on torsional modulus and internal stiffeners could lead to large variations when subject to large load cases. Furthermore, the static load tests were performed using smaller forces than the ones at which the foil was subject in the cavitation tunnel, leading to uncertainties on the assumption of linear variations in displacement and more in detail in twist. Differences in deflection and twist, indeed lead to discrepancies in the three force components. 


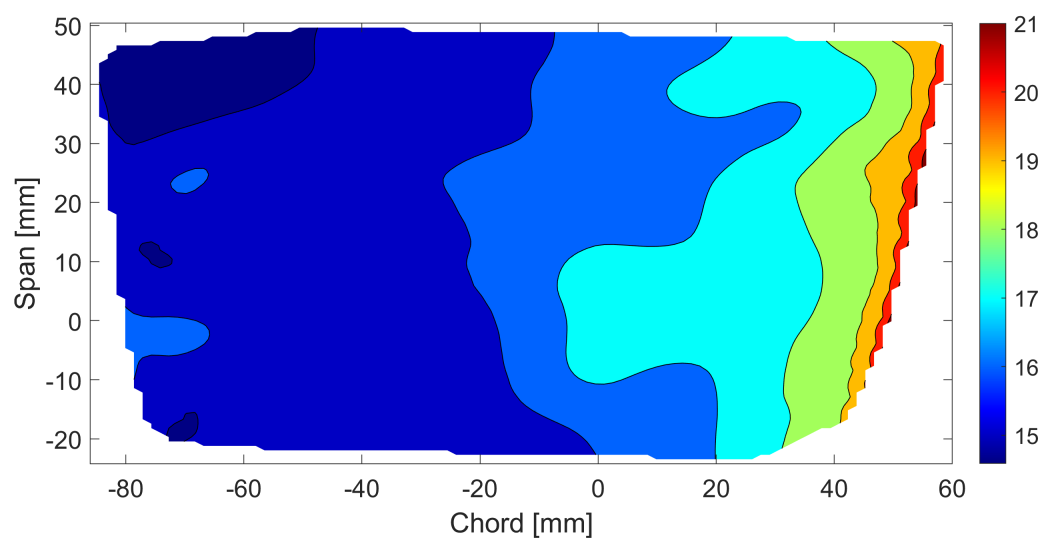

(a) Difference in $\mathrm{mm}$ between experimental DIC and numerical FSI deflection with the numerical simulations experiencing a smaller displacement compared to the measured one.

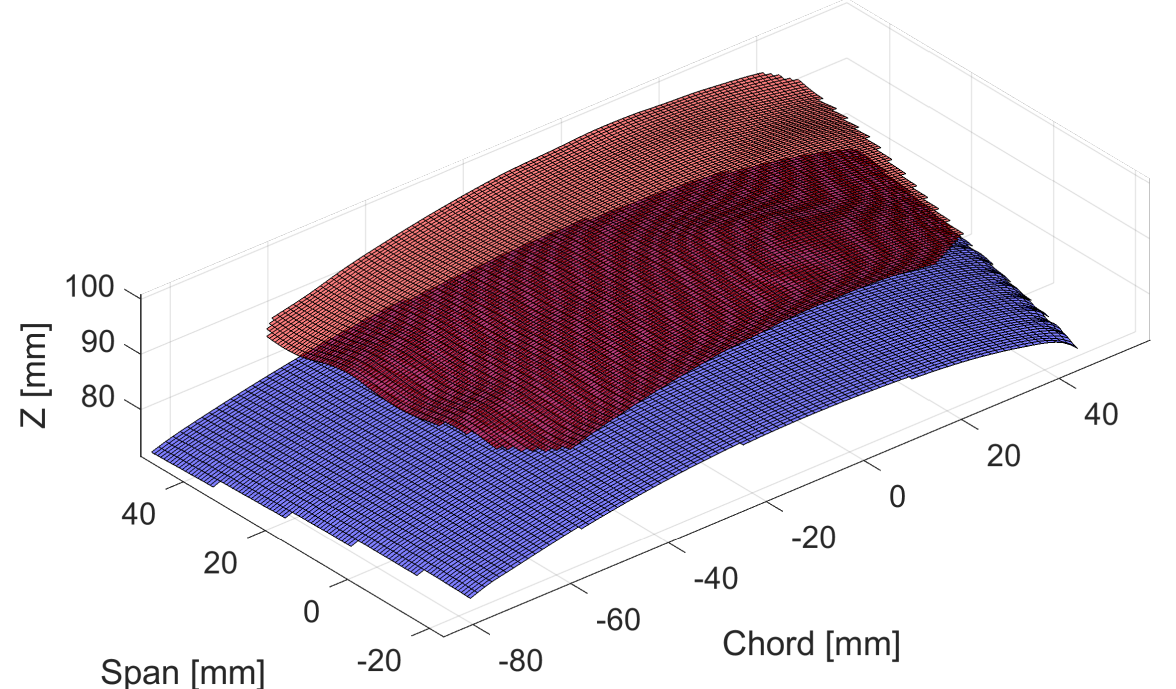

(b) Surface representation difference between experimental DIC and numerical FSI.

Figure 35. Surface representation and deflection difference as measured by DIC and simulated numerically for the case where rake and leeway angles are set to zero (T0R0).

To accurately simulate the structural response of the hydrofoil, the composite material characteristics of the hydrofoil, including a correct layup angle and lamina thickness, have to be obtained and implemented in the structural analysis solver. The internal structure of the hydrofoil plays an important role in its structural responses. Therefore, the details of the internal stiffeners also has to be taken into account in the simulations. Further work will therefore focus on improving the knowledge of materials and internal layup.

A series of different factors, which are mainly related to the simplifications made to the foil internal stiffener, composite stack layout and thickness and its material properties, were discussed above to explain the reasons for the observed discrepancies between the computed and the measured results. A few additional sources of uncertainties which may contribute to the discrepancies are discussed below.

The accuracy of the leeway rotational angles measurement is one of the aforementioned uncertainties. Being a complex 3D foil, it was not possible to set the zero leeway angle only by inspecting the drag component. The foil was therefore placed at zero leeway angle 
inside the tunnel, ensuring that the same distance was achieved for the leading and trailing edges to the side walls, adding a possible human error in the overall results.

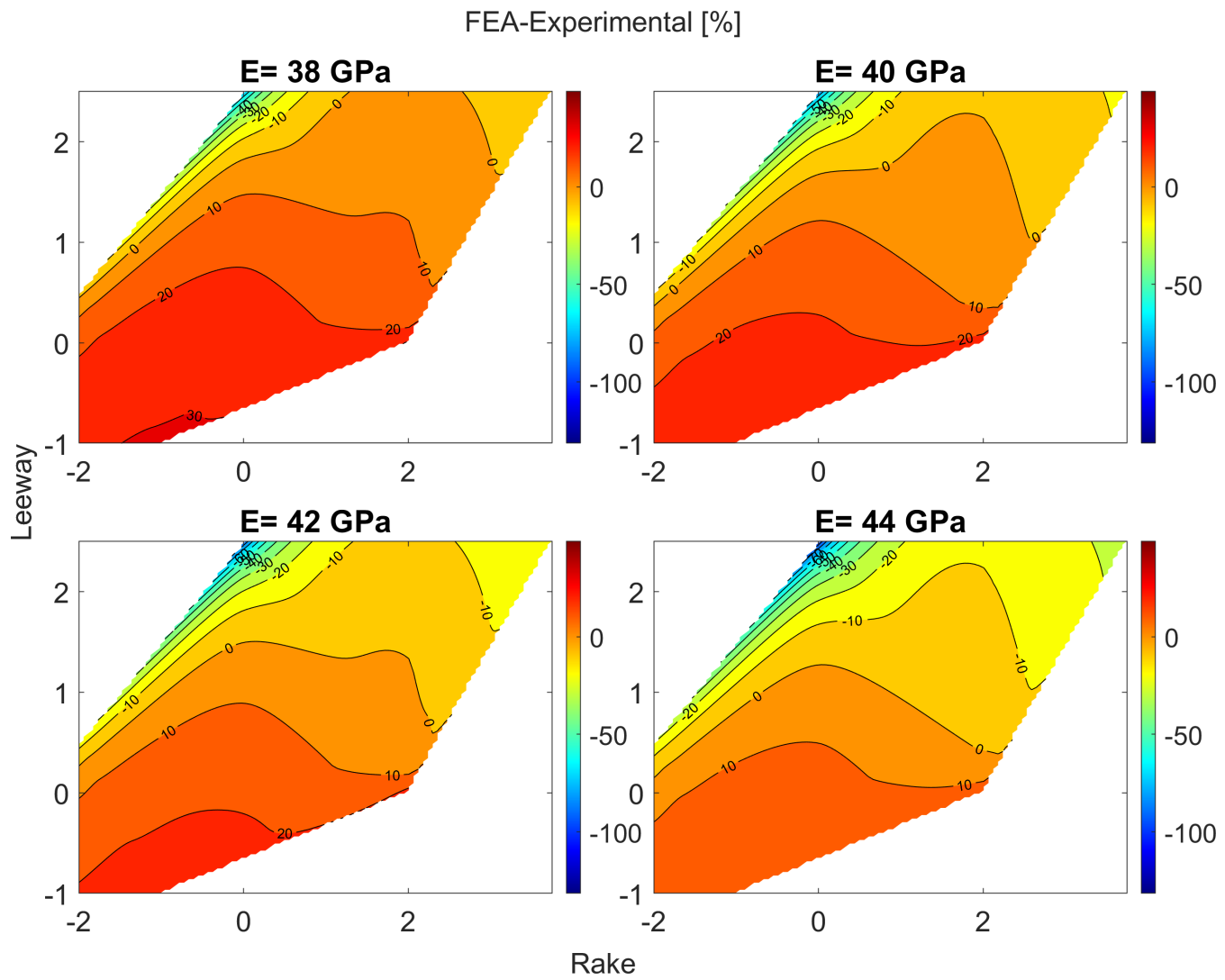

Figure 36. Impact on average displacement with respect to the Young's modulus.

Moreover, the uncertainty related to the flow speed measurement in the cavitation tunnel may also contribute to the difference in overall results. The flow velocity at the cavitation tunnel test section is obtained from pitot tube measurements, however, based on the mass continuity equation, the flow speed in the computations is set on the inlet boundary with the aim to have the same flow speed at test section.

\section{Conclusions}

A series of experimental and numerical results that indicate the performance of a NACRA 17 Z-Foil in different operating conditions is presented in this research. The objective is to develop experimental and computational methods for understanding fluidstructure interaction of three-dimensional composite hydrofoils including the interaction between hydrofoil deflections and the forces acting on the hydrofoil and vice-versa. Such interactions can lead to changes in sailing conditions. Therefore, understanding the coupling between the hydrodynamics and structural response of hydrofoils can lead to new designs, which in turn can improve the performance of foiling craft.

The experimental tests were conducted in SSPA's cavitation tunnel. The hydrofoil deflection was measured using DIC and simultaneously the forces and moments were measured with the tunnel balance. In certain conditions the foil deflection can be as large as $24 \%$ of its immersed span, which drastically changes the underwater shape and thus the performance of the foil, especially affecting the lift and side force generation. The data collected from the tests formed a basis for reverse engineering the material properties of the Z-Foil without the need for destructive tests.

The numerical simulations are carried out through a two-way coupling between a Reynolds-Averaged Navier-Stokes solver and a Finite Element Analysis solver. The results obtained from the simulations are compared against the measured data. Since the details 
of the material properties of the carbon fiber composite hydrofoil were unknown, it was assumed that the hydrofoil is made of an isotropic linear elastic material. A series of static load tests were carried out on the composite hydrofoil to estimate the material properties on an equivalent hydrofoil made of isotropic material. In average, the computed lift and drag of the deflected hydrofoil deviates about $20 \%$ and $35 \%$ from the measured values, respectively. However, the computational method fails to predict the details of the hydrofoil deflections in the simplistic isotropic material chosen mainly due to unknowns in torsional stiffness, location and geometry of internal stiffener, and most importantly the tapering and placement of composite layers. Differences in deflection and twist indeed lead to discrepancies in the three force components.

From the experimental campaign, an important conclusion could be drawn and reported to the sailing community. In the NACRA 17 Z-Foil, minimum drag occurs at different combinations of leeway angles, whereas the lift and side force distributions can be more linearly correlated to leeway and rake angle changes. The quadratic trend of $D$ leads to the necessity of choosing a trade-off between low drag setups and maximum lift generation. Different configurations of rake for the windward and leeward foils could be set to minimize the overall drag, also named as differential angle. To obtain minimum drag from the two Z-foils, the rake can be set to negative for the windward foil and to positive for leeward foil, $R=-2^{\circ}$ and $R=2 ; 2.5^{\circ}$ respectively. The differential configuration would indeed affect the righting moment $M_{Y}$, leading to a range of different crew weight possibilities.

Author Contributions: The authors of the paper have contributed in a similar way both in the production of the results and in the write up of the manuscript. All authors have read and agreed to the published version of the manuscript.

Funding: Hugo Hammar's funding from SSPA and Rolf Sörman's funding from Chalmers University of Technology are acknowledged for providing the financial support to run the experimental tests at SSPA. This study received also funding from Chalmers University of Technology Foundation for the strategic research project Hydro-and aerodynamics.

Institutional Review Board Statement: Not applicable.

Informed Consent Statement: Not applicable.

Acknowledgments: The authors would like to thank Alex Nila from LaVision for providing assistance during the setup of the DIC equipment. The authors would also like to thank the laboratory and workshop technicians in SSPA Sweden AB as well as Jan Hallander, who ran the experiments. Rikard Karlsson from Chalmers CASE Lab is acknowledged for his assistance in 3D-scanning the foil. The simulations were performed on high-performance computing resource (Tetralith) at the National Supercomputer Centre at Linköping University (NSC) provided by the Swedish National Infrastructure for Computing (SNIC).

Conflicts of Interest: The authors declare no conflict of interest. The funding bodies had no role in the design of the study; in the collection, analyses, or interpretation of data; in the writing of the manuscript, or in the decision to publish the results.

\section{References}

1. NACRA Sailing. NACRA 17 Specifications. Available online: https://nacra17.org/nacra17/ (accessed on 7 June 2021).

2. Guida, P.; Marimon Giovannetti, L.; Boyd, S.W. Three-dimensional variations of the NACRA 17 main foil for benchmarking shape optimizations. In Proceedings of the 5th International Conference on Innovation in High Performance Sailing Yachts and Sail-Assisted Ship Propulsion, INNOVSAIL, Gothenburg, Sweden, 15-17 June 2020.

3. Marimon Giovannetti, L.; Stenius, I. Review of underwater Fluid-Structure Interaction measuring techniques. In Proceedings of the 7th High Performance Yacht Design Conference, Auckland, New Zealand, 11-12 March 2021.

4. Bazilevs, Y.; Takizawa, K.; Tezduyar, T.E. Computational Fluid-Structure Interaction: Methods and Applications; Elsevier Ltd.: Amsterdam, The Netherlands , 2014.

5. Zienkiewicz, O.C.; Taylor, R.L.; Nithiarasu, P. The Finite Element Method for Fluid Dynamics, 7th ed.; John Wiley and Sons: Hoboken, NJ, USA , 2013. 
6. Manudha, H.T.; Lee, A.K.L.; Prusty, G.B. Design of Shape-Adaptive Wind Turbine Blades Using Differential Stiffness Bend-Twist Coupling. Ocean Eng. 2015, 95, 157-165.

7. Manudha, H.T.; Phillips, A.W.; St John, N.; Brandner, P.; Pearce, B.; Prusty, G. Hydrodynamic Response of a Passive ShapeAdaptive Composite Hydrofoil. Mar. Struct. 2021, 80, 103084.

8. Vanilla, T.T.; Benoit, A.; Benoit, P. Hydro-elastic response of composite hydrofoil with FSI. Ocean Eng. 2021, 221, 108230. [CrossRef]

9. Pernod, L.; Ducoin, A.; Le Sourne, H.; Astolfi, J.A.; Casari, P. Experimental and Numerical Investigation of the Fluid-Structure Interaction on a Flexible Composite Hydrofoil under Viscous Flows. Ocean Eng. 2021, 194, 106647. [CrossRef]

10. López, I.; Piquee, J.; Bucher, P.; Bletzinger, K.U.; Breitsamter, C.; Wüchner, R. Numerical Analysis of an Elasto-Flexible Membrane Blade Using Steady-State Fluid-Structure Interaction Simulations. J. Fluids Struct. 2021, 106, 103355. [CrossRef]

11. Antoine, D.; Astolfi, J.A.; Sigrist, J.F. An Experimental Analysis of Fluid Structure Interaction on a Flexible Hydrofoil in Various Flow Regimes Including Cavitating Flow. Eur. J. Mech. B Fluids 2012, 36, 63-74.

12. SAP Sailing Analytics. Olympic Summer Games 2020 Tokyo. 2021. Available online: https://tokyo2020.sapsailing.com/ (accessed on 2 August 2021).

13. Graf, K.; Freiheit, O. VPP-driven sail and foil trim optimization for the Olympic NACRA 17 foiling catamaran. In Proceedings of the 5th International Conference on Innovation in High Performance Sailing Yachts and Sail-Assisted Ship Propulsion, INNOVSAIL, Gothenburg, Sweden, 15-17 June 2020.

14. Casanueva, J. Report following Conclusion of Disciplinary Process Iker Martinez (ESP 70), Santander. 2019. Available online: https: / / www.sailing.org/tools/documents / MartinezReport-[24818].pdf (accessed on 2 August 2021).

15. Crammond, G.; Boyd, S.W.; Dulieu-Barton, J.M. Speckle pattern quality assessment for digital image correlation. Opt. Lasers Eng. 2013, 51, 1368-1378. [CrossRef]

16. Mccormick, N. Digital image correlation for structural measurements. Proc. Inst. Civ. Eng. 2012, 165, 185-190. [CrossRef]

17. Tang, Z.; Liang, J.; Xiao, Z.; Guo, C. Large deformation measurement scheme for 3D digital image correlation method. Opt. Lasers Eng. 2012, 50, 122-130. [CrossRef]

18. Rastogi, P.K.; Hack, E. Optical Methods for Solid Mechanics: A Full-Field Approach; Wiley-VCH: Weinheim, Germany , 2012.

19. Marimon Giovannetti, L.; Banks, J.; Ledri, M.; Turnock, S.R.; Boyd, S.W. Toward the development of a hydrofoil tailored to passively reduce its lift response to fluid load. Ocean Eng. 2018, 167, 1-10. [CrossRef]

20. Banks, J.; Marimon Giovannetti, L.; Soubeyran, X.; Wright, A.M.; Turnock, S.R.; Boyd, S.W. Assessment of Digital Image Correlation as a method of obtaining deformations of a structure under fluid load. J. Fluids Struct. 2015, 58, 173-187. [CrossRef]

21. Marimon Giovannetti, L.; Banks, J.; Turnock, S.R.; Boyd, S.W. Uncertainty assessment of coupled Digital Image Correlation and Particle Image Velocimetry for fluid-structure interaction wind tunnel experiments. J. Fluids Struct. 2017, 68, 125-140. [CrossRef]

22. International Towing Tank Conference, Propulsion; Cavitation Induced Erosion on Propellers, Rudders and Appendages Model Scale Experiments. In ITTC—Recommended Procedures and Guidelines; rev 1; 2005 . Available online: https://www.wartsila.com/ encyclopedia/term/international-towing-tank-conference-(ittc) (accessed on 2 August 2021).

23. Jacobson, R.E.; Ray, S.F.; Attridge, G.G.; Axford, N.R. The Manual of Photography: Photographic and Digital Imaging; Focal Press: Waltham, MA, USA , 2000.

24. Ferziger, J.H.; Perić, M. Computational Methods for Fluid Dynamics, 3rd ed.; Springer: Berlin/Heidelberg, Germany, 1999.

25. Demirdžić, I.; Muzaferija, S. Numerical Method for Coupled Fluid Flow, Heat Transfer and Stress Analysis Using Unstructured Moving Meshes with Cells of Arbitrary Topology. In Computer Methods in Applied Mechanics and Engineering; Elsevier Ltd.: Amsterdam, The Netherlands, 1995; Volume 125, pp. 235-255.

26. Weiss, J.; Maruszewski, J.P.; Smith, W.A. Implicit Solution of Preconditioned Navier-Stokes Equations Using Algebraic Multigrid. AIAA J. 1999, 37, 29-36. [CrossRef]

27. Eça, L.; Hoekstra, M. A procedure for the estimation of the numerical uncertainty of CFD calculations based on grid refinement studies. J. Comput. Phys. 2014, 262, 104-130. [CrossRef]

28. Pate, D.J.; German, B.J. Lift distributions for minimum induced drag with generalized bending moment constraints. J. Aircr. 2013, 50, 936-946. [CrossRef]

29. MathWorks, Computer Vision. Mathworks. 2021. Available online: https://se.mathworks.com/products/computer-vision.html (accessed on 23 May 2021). 